Full length article

\title{
Evaluation of the anti-oxidative and ROS scavenging properties of biomaterials coated with epigallocatechin gallate for tissue engineering
}

\author{
Sangmin Lee ${ }^{\mathrm{a}, \mathrm{b}}$, Jinkyu Lee ${ }^{\mathrm{a}}$, Hayeon Byun ${ }^{\mathrm{a}, \mathrm{b}}$, Se-jeong Kim ${ }^{\mathrm{a}, \mathrm{b}}$, Jinmyoung Joo ${ }^{\mathrm{c}}$, \\ Hee Ho Park ${ }^{\mathrm{d}}$, Heungsoo shin ${ }^{\mathrm{a}, \mathrm{b}, \mathrm{e}, *}$ \\ a Department of Bioengineering, Hanyang University, 222 Wangsimni-ro, Seongdong-gu, Seoul, 04763, Republic of Korea \\ ${ }^{b}$ Education and Research Group for Biopharmaceutical Innovation Leader, Hanyang University, Republic of Korea \\ ${ }^{c}$ Department of Biomedical Engineering, Ulsan National Institute of Science and Technology (UNIST), Ulsan, 44919, Republic of Korea \\ ${ }^{\mathrm{d}}$ Department of Biotechnology and Bioengineering, Kangwon National University, Chuncheon, Gangwon-do, 24341, Republic of Korea \\ ${ }^{\mathrm{e}}$ Institute of Nano Science and Technology, Hanyang University, Republic of Korea
}

\section{A R T I C L E I N F O}

\section{Article history:}

Received 2 November 2020

Revised 2 February 2021

Accepted 2 February 2021

Available online 6 February 2021

\section{Keywords:}

Tissue engineering

Oxidative stress

Reactive oxygen species

Antioxidant

Polyphenol coating

\begin{abstract}
A B S T R A C T
In tissue engineering, excessively generated reactive oxygen species (ROS) during biomaterial implantation or cell transplantation is a one of major causes of diminishing therapeutic effects. In this study, we prepared biomaterial surfaces coated with antioxidant epigallocatechin gallate (EGCG) and metal ions, and evaluated their anti-oxidative and ROS scavenging properties. We revealed that EGCG-coating on polycaprolactone (PCL) film surface increased hydrophilicity and anti-oxidative properties as a function of total phenol content (TPC) potentially due to the increase in phenolic $-\mathrm{OH}$ and $\pi$-electrons from structural maintenance and directly removed the hydrogen peroxide $\left(\mathrm{H}_{2} \mathrm{O}_{2}\right)$ by resonance-stabilization. Furthermore, EGCG-coated PCL film increased attachment, spreading area, and viability of human adipose-derived stem cells (hADSCs) against $\mathrm{H}_{2} \mathrm{O}_{2}$ treatment while stimulated the cellular signaling to reduce apoptotic gene and enhance anti-oxidative enzyme expression. Further, we applied EGCG coating on the surface of polyL-lactic acid (PLLA) fibers. Spheroids incorporating EGCG-coated PLLA fibers were able to maintain their shape and showed improved viability and anti-oxidative activities in response to $\mathrm{H}_{2} \mathrm{O}_{2}$-induced oxidative stress than control spheroids. Therefore, metal-phenolic network (MPN) coating of EGCG is a suitable method to impart the anti-oxidative properties to biomaterials by evaluating the structural properties and biological effects.
\end{abstract}

\section{Statement of Significance}

This manuscript describes an antioxidant coating for biomaterials to control reactive oxygen species (ROS). Antioxidant epigallocatechin gallate (EGCG) was coated on the PCL film surface via metal-phenolic network (MPN). We revealed that the phenolic functional groups of EGCG are structurally maintained as confirmed by quantitative reducing power, radical scavenging assays. EGCG coating not only removed ROS directly, but also is involved in cell signaling to enhance the anti-apoptotic gene, anti-oxidative enzyme expression. Furthermore, human adipose-derived stem cells (hADSCs) spheroid produced by self-assembly with EGCG-coated poly-L-lactic aicd (PLLA) fibers showed anti-oxidative properties from inside of spheroids. Thus, our evaluation of the anti-oxidative properties of EGCG coating can be applied to various tissue engineering applications.

(C) 2021 Acta Materialia Inc. Published by Elsevier Ltd. All rights reserved.

\footnotetext{
* Corresponding author.

E-mail address: hshin@hanyang.ac.kr (H. shin).
}

\section{Introduction}

Reactive oxygen species (ROS), including superoxide $\left(\cdot \mathrm{O}_{2}^{-}\right)$, hydrogen peroxide $\left(\mathrm{H}_{2} \mathrm{O}_{2}\right)$, and hydroxyl radicals $(\cdot \mathrm{OH})$, are generally produced during implantation of biomaterials or cells for tissue 
engineering therapy. Excessive ROS cause apoptosis and activation of inflammatory signaling cascades, leading to incomplete recovery of damaged tissue [1,2]. For example, the high level of ROS surrounding dental implants results in uncontrolled inflammation with bone loss, and elevation of ROS during autologous or allogenic hematopoietic stem cell transplantation (HSCT) can result in serious toxic problems [3-5]. It has been reported that pro-oxidant methemoglobin $\left(\mathrm{Fe}^{3+}\right)$ released from lysed blood cells and $\mathrm{H}_{2} \mathrm{O}_{2}$ derived from the lysis of epithelial or immune cells during surgical incision of implantation process are associated with ROS-mediated failure of tissue engineering approaches [6,7]. In addition, serum proteins adsorbed to the surfaces of biomaterials are known to bind to Fc domains of transmembrane receptors of inflammatory cells, stimulating the synthesis of ROS by these cells $[8,9]$. Therefore, it is important to control ROS for successful regenerative outcomes in tissue engineering.

Various strategies based on the use of antioxidants and antioxidative enzymes have been investigated to control ROS. For example, delivery of the soluble antioxidant $\mathrm{N}$-acetylcysteine (NAC) with mesenchymal stem cell (MSC) aggregates into ischemic tissue successfully removed $80 \%$ of $\mathrm{H}_{2} \mathrm{O}_{2}$ with enhancement of cell adhesion and survival of the engrafted cells [10]. Furthermore, delivery of the soluble antioxidant edaravone with human umbilical cord mesenchymal stem cells (hUMSCs) in an acute liver failure model increased the viability of transplanted hUMSCs by 1.5 -fold and reduced the area of hepatic necrosis by approximately 60\% [11]. However, co-injected soluble antioxidants or antioxidative enzymes were rapidly cleared (8-90\% within $24 \mathrm{hr}$ ), and therefore, ineffective for continuous control of ROS generated by damaged tissue $[12,13]$. As an alternative, biomaterials have been mixed or surface-coated with antioxidant or anti-oxidative enzymes to achieve sustained anti-oxidative activity. For example, polycaprolactone (PCL)/polyethylene glycol (PEG) electrospun nanofibers mixed with antioxidant chrysin significantly reduced chrysin release with 1,000-fold greater oxygen radical decomposition capacity than control nanofibers, while hyaluronic acid hydrogels conjugated with anti-oxidative dopamine showed $40 \%$ and $65 \%$ improved hydroxyl radical and DPPH scavenging activity over nonconjugated hydrogels, respectively, with increased SOD and GPX enzyme activity $[14,15]$. However, mixing of ROS-controlling agents with biomaterials may alter the characteristics of biomaterials such as their degradation rate, swelling ratio, and mechanical properties, while the surface conjugating strategy may require complex chemical processes and could decrease the biological activities of antioxidants or anti-oxidative enzymes [14-16].

Polydopamine and polyphenol coating of biomaterials have been actively studied. Polydopamine forms a material-independent coating on the biomaterial surface at a basic $\mathrm{pH}$ by self-oxidation of catechol groups in dopamine [17]. Similarly, polyphenols such as tannic acid (TA), catechin (CA), and epigallocatechin gallate (EGCG) can readily form a metal-phenolic network (MPN) with cationic metal ions due to hydrogen bonding, $\pi-\pi$ stacking, and cation- $\pi$ interactions by incubation of the sample in a buffer solution containing metal ions such as $\mathrm{Na}^{+}, \mathrm{Fe}^{3+}$ [18]. In particular, an MPN can form on the surfaces of various types of materials, facilitating simple and effective coating and conferring that material with the biological properties of polyphenols including their anti-inflammatory, anti-cancer, and anti-oxidative properties [19]. For example, gold nanoparticles coated with polyphenols in the presence of $\mathrm{HAuCl}_{4} \cdot 3 \mathrm{H}_{2} \mathrm{O}$ showed $46 \%, 51 \%$, and $55 \%$ ABTS radical scavenging activity when coated with EGCG, resveratrol (RSV), and fisetin (FS), respectively [20]. Furthermore, tissue culture polystyrene (TCP) coated with TA modified with $\mathrm{Na}^{+}$coated silica nanoparticles reduced the intracellular ROS level significantly more than uncoated TCP [21]. In addition, MPN coatings have been reported to have anti-cancer activity (coating of $\mathrm{RSV}$ with $\mathrm{Au}^{3+}$ ) and to enhance endothelialization (coating of $\mathrm{TA}$ with $\mathrm{Sr}^{2+}$ ) [2224]. Despite the focus on using polyphenols as surface modifiers of biomaterials, detailed information on the effects of coating concentration and structural feature of polyphenols on anti-oxidative activity and cellular signaling have not yet been reported.

Previously, our group reported the EGCG coating on Ti surface in the presence of $\mathrm{Mg}^{2+}$, and investigated their effect on osteogenic differentiation of human adipose-derived stem cells (hADSCs) and suppression of osteoclast functions [25]. Compared to this previous work, the current study is focused on the evaluation of the anti-oxidative properties of EGCG-coated biomaterial surfaces and their effects on cells, based on the structural and chemical properties of EGCG through 2D and 3D culture conditions for hADSCs. Given that, we prepared PCL films and poly-L-lactic acid (PLLA) fibers coated with EGCG as model substrates, and then, analyzed the effect of coating in the presence of cations $\left(\mathrm{Na}^{+}\right.$or $\mathrm{Mg}^{2+}$ ) on the total phenol content (TPC) deposited on the surfaces of the substrates, surface properties, and anti-oxidative properties. Second, we cultured hADSCs on EGCG-coated surfaces and investigated the effect of the EGCG coating on the survival of hADSCs under a ROS environment induced by $\mathrm{H}_{2} \mathrm{O}_{2}$ treatment. In addition, PLLA fibers coated with EGCG were combined with hADSCs to prepare 3D spheroids and we examined whether the EGCG-coated fibers were able to protect stem cells within the spheroids from oxidative stress.

\section{Materials and methods}

Polycaprolactone (PCL) $\left(\mathrm{M}_{\mathrm{w}}=80,000\right)$ and poly-L-lactic acid (PLLA, 1479) were obtained from Sigma-Aldrich (St. Louis, MO, USA) and Samyang (Jeollabuk-do, Korea), respectively. 2,2,2trifluoroethanol (TFE) and ethylenediamine (EDM) were purchased from Sigma-Aldrich (St. Louis, MO, USA). Dichloromethane (DCM) and isopropyl alcohol (IPA) were purchased from Junsei Chemical Co., Ltd (Chuo-ku, Tokyo, Japan) and EDM Millipore (Darmstadt, Germany), respectively. BIS-TRIS was obtained from SigmaAldrich (St. Louis, MO, USA), and EGCG was purchased from TCI America. Magnesium chloride hexahydrate $\left(\mathrm{MgCl}_{2} \cdot 6 \mathrm{H}_{2} \mathrm{O}\right)$ and sodium chloride $(\mathrm{NaCl})$ were obtained from Junsei Chemical Co., Ltd. Distilled water (D.W.) was acquired from an Elix Advantage System (Millipore, MA, USA). Phosphate buffered saline (PBS), trypsin/EDTA, fetal bovine serum (FBS), and penicillin-streptomycin (PS) were purchased from Wisent (St. Bruno, QC, Canada). MesenPro RS medium and L-glutamine were obtained from Gibco BRL (Rockville, MD, USA). Human adipose-derived stem cells (hADSCs) were purchased from Invitrogen (Carlsbad, CA, USA). 3\% hydrogen peroxide $\left(\mathrm{H}_{2} \mathrm{O}_{2}\right)$ was purchased from Sigma-Aldrich (St. Louis, MO, USA). LIVE/DEAD assay kit and Alexa Fluor ${ }^{\mathrm{TM}} 488$ Phalloidin were purchased from Invitrogen (Carlsbad, CA, USA). Mounting medium containing 4',6-diamidino-2-phenylindole was purchased from Vectashield $₫$ (Burlingame, CA, USA). The RNeasy Mini Kit was obtained from Qiagen (Valencia, CA, USA). Maxime RT Premix was purchased from Intron (Seoul, Korea), and SYBR Premix Ex Taq was acquired from TAKARA (Otsu, Shiga, Japan).

\subsection{Preparation and characterization of EGCG-coated PCL films}

To prepare PCL films, PCL granules $(4 \mathrm{~g})$ were dissolved in 50 $\mathrm{ml}$ of dichloromethane (DCM) and 2,2,2-trifluoroethanol (TFE) (8:2, $\mathrm{v} / \mathrm{v}$ ) for $24 \mathrm{hr}$, and this solution was then poured into a $100 \mathrm{~mm}$ glass dish and thoroughly dried in a $60^{\circ} \mathrm{C}$ dry oven for $6 \mathrm{hr}$. Circles were punched from the dried PCL film (diameter, $1.91 \mathrm{~cm}^{2}$ ). $1 \mathrm{mM}$ EGCG solution was prepared in BIS-TRIS buffer $(100 \mathrm{mM}$ of BISTRIS in D.W. at pH 7). We added either $300 \mathrm{mM}$ of $\mathrm{NaCl}$ or $\mathrm{MgCl}_{2}$ to the buffer solution for MPN formation. PCL film was placed on a 24-well plate and incubated with $1 \mathrm{ml}$ of EGCG solution for $24 \mathrm{hr}$ 
at $37^{\circ} \mathrm{C}$. The total phenol content (TPC) on the PCL films was determined using the Folin-Ciocalteu method. Briefly, films were incubated with $300 \mu \mathrm{L}$ Folin-Ciocalteu solution for $10 \mathrm{~min}$, and then $700 \mu \mathrm{L}$ of sodium carbonate solution $\left(\mathrm{Na}_{2} \mathrm{CO}_{3}, 2 \% \mathrm{w} / \mathrm{v}\right)$ was added. After a 2-hr incubation at RT, absorbance was measured at $780 \mathrm{~nm}$. The TPC on the PCL film was calculated using an EGCG standard. The same concentration $(300 \mathrm{mM})$ of buffer solutions containing different monovalent $(\mathrm{NaCl}, \mathrm{KCl})$ and divalent $\left(\mathrm{MgCl}_{2}, \mathrm{CaCl}_{2}\right.$, and $\mathrm{SrCl}_{2}$ ) metal ions were used for the EGCG coating on PCL film surface with same method described above. The relative TPC on PCL film was calculated by using the same Folin-Ciocalteu method and normalization with the values from the use of $\mathrm{NaCl}$ and $\mathrm{MgCl}_{2}$, respectively. The EGCG-coated PCL films were incubated in $1 \mathrm{ml}$ of D.W. for $1,2,4$, and 7 days to measure the remaining TPC on the surface. The relative TPC of Surface functional groups on the PCL film were analyzed by attenuated total reflection-Fourier transform infrared spectroscopy (ATR-FTIR, Nicolet 6700, Thermo Scientific, Waltham, MA, USA) and the surface atomic composition of PCL film was analyzed by X-ray photoelectron spectrometry (XPS) (ThetaProbe Base System, Thermo Fisher Scientific) at the Hanyang Center for Research Facilities (Seoul) using analysis software (Thermo VG Scientific, MA, USA). Surface morphological changes were observed using scanning electron microscopy (SEM) (Hitachi S-4800, Hitachi, Ltd, Tokyo, Japan). Water contact angle was measured by capturing images (Phoenix 300, Surface Electro Optics Co., Suwon, Korea) of a $1 \mu$ d droplet of D.W. on the surface of the PCL films and analyzing them with Image-Pro plus software (MediaCybernetics, Silver Spring, MD, USA).

Anti-oxidative properties of EGCG-coated PCL films were analyzed using a ferric reducing antioxidant power assay and ABTS radical scavenging assay. For the ferric reducing antioxidant power assay, $1 \mathrm{mg} / \mathrm{ml}$ of 1,10-phenanthroline and $1 \mathrm{mM}$ of $\mathrm{FeCl}_{3}$ (SigmaAldrich, St. Louis, MO, USA) were dissolved in D.W. to obtain an $\mathrm{Fe}(\mathrm{III})$ solution. Prewetted EGCG-coated PCL films were mixed with $1 \mathrm{ml}$ of $\mathrm{Fe}(\mathrm{III})$ solution, and the absorbance of the solution was measured at $510 \mathrm{~nm}$ and used to quantify the conversion ratio of $\mathrm{Fe}(\mathrm{III})$ to $\mathrm{Fe}(\mathrm{II})$ (\%) calculated using an ascorbic acid standard. ABTS radicals were generated in a solution contain-

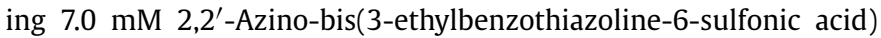
diammonium salt and $2.4 \mathrm{mM}$ potassium persulfate $\left(\mathrm{K}_{2} \mathrm{~S}_{2} \mathrm{O}_{8}\right)$ (Sigma-Aldrich, St. Louis, MO, USA) in D.W. for 24 hr. The ABTS solution was diluted with PBS until an absorbance value of 0.7 at $732 \mathrm{~nm}$ was reached and then mixed with $50 \mu \mathrm{l}$ of ascorbic acid standard or EGCG-coated PCL film prewetted with $50 \mu$ D.W. After 10 min of reaction, the percentage ABTS radicals scavenged was calculated by measuring the absorbance of the solution at $732 \mathrm{~nm}$.

\subsection{Adhesion of hADSCS and ROS-scavenging activity of EGCG-coated PCL films}

hADSCs were maintained under standard culture conditions with MesenPro RS medium (with 1\% L-glutamine and 1\% PS) and cells from passage number 4 were used in all experiments. To determine the effect of EGCG on the viability of hADSCs, hADSCs were seeded in a tissue culture plate at $0.5 \times 10^{4}$ cells $/ \mathrm{cm}^{2}$ and cultured for $24 \mathrm{hr}$. Then, the media was replaced with fresh medium containing EGCG $(0,12.5,25,50 \mu \mathrm{M})$ and the viability of hADSCs was measured by MTT assay after a 24-hr incubation. hADSCs were seeded at $0.5 \times 10^{4}$ cells $/ \mathrm{cm}^{2}$ on the surface of PCL film and EGCG-coated PCL film and cultured for $24 \mathrm{hr}$. hADSCs cultured on PCL film were fixed with $4 \%$ paraformaldehyde, and then incubated with 1:200 Alexa Fluor ${ }^{\mathrm{TM}} 488$ Phalloidin for $1 \mathrm{hr}$ at $37^{\circ} \mathrm{C}$ for F-actin staining. hADSCs stained for F-actin were preserved using mounting medium with DAPI. The number of attached cells was calculated by counting the number of nuclei per area $\left(/ \mathrm{mm}^{2}\right)$, and spread area was calculated by measuring the existing area $\left(\times 10^{3}\right.$ $\mu \mathrm{m}^{2}$ ) of actin filaments per individual cells using Image-Pro plus software.

We first investigated the effect of the concentration of exogenous $\mathrm{H}_{2} \mathrm{O}_{2}$ on the viability of hADSCs; hADSCs were cultured on a tissue culture plate at $0.5 \times 10^{4}$ cells $/ \mathrm{cm}^{2}$ for $24 \mathrm{hr}$ and the medium was replenished by fresh medium containing $0,100,200$, or $400 \mu \mathrm{M} \mathrm{H}_{2} \mathrm{O}_{2}$. Cell viability was then measured by MTT assay after 4, 8, and $24 \mathrm{hr}$. To investigate the effect of EGCG on ROS scavenging, hADSCs were similarly cultured on a tissue culture plate at $0.5 \times 10^{4}$ cells $/ \mathrm{cm}^{2}$, and the culture media was then replaced by one containing $\mathrm{H}_{2} \mathrm{O}_{2}(100 \mu \mathrm{M})$ and $0,12.5,25$, or $50 \mu \mathrm{M}$ of EGCG. After $24 \mathrm{hr}$ of culture, cell viability was measured by MTT assay. We then cultured hADSCs on the surfaces of PCL film and EGCGcoated PCL film for $24 \mathrm{hr}$ and exposed the hADSCs on the film to $200 \mu \mathrm{M}$ of $\mathrm{H}_{2} \mathrm{O}_{2}$-containing culture media for $12 \mathrm{hr}$. The number of cells before and after $\mathrm{H}_{2} \mathrm{O}_{2}$ treatment were counted and morphological changes were observed after F-actin staining.

\subsection{Anti-apoptotic and anti-oxidative activities of EGCG-coated PCL film against $\mathrm{H}_{2} \mathrm{O}_{2}$}

Apoptotic DNA fragmentation of hADSCs cultured on PCL and EGCG-coated PCL films in response to $\mathrm{H}_{2} \mathrm{O}_{2}$ treatment was analyzed by TUNEL assay (ApopTag ${ }^{\circledR}$ fluorescein in situ apoptosis detection kit, Sigma-Aldrich, St. Louis, MO, USA). hADSCs at $0.5 \times 10^{4}$ cells $/ \mathrm{cm}^{2}$ were cultured on the surfaces of PCL and EGCG-coated PCL films for $24 \mathrm{hr}$, and the films were then exposed to 200 $\mu \mathrm{M}$ of $\mathrm{H}_{2} \mathrm{O}_{2}$ for $12 \mathrm{hr}$. $\mathrm{H}_{2} \mathrm{O}_{2}$-exposed cells on PCL films were fixed with $1 \%$ paraformaldehyde for $10 \mathrm{~min}$ and then treated with ethanol:acetic acid (2:1, v:v) for $5 \mathrm{~min}$. After two washes with PBS, equilibration buffer was added for $10 \mathrm{sec}$. Then, the cells were incubated with terminal deoxynucleotide transferase (TDT) for $1 \mathrm{hr}$ in a $37^{\circ} \mathrm{C}$ incubator. Immediately after TDT treatment, stop/wash buffer was added for $10 \mathrm{~min}$ at RT, followed by addition of anti-digoxigenin conjugate (fluorescein) for $30 \mathrm{~min}$. Stained cells were preserved in mounting medium with DAPI. Percentage TUNEL-positive nuclei was calculated by counting the number of fluorescein-stained nuclei (positive) and normalizing this to the total number of nuclei.

To examine the ability of EGCG-coated film to scavenge $\mathrm{H}_{2} \mathrm{O}_{2}$, PCL and EGCG-coated PCL films were incubated in D.W. containing $100 \mu \mathrm{M} \mathrm{H} \mathrm{O}_{2}$ for $2 \mathrm{hr}$ and the remaining $\mathrm{H}_{2} \mathrm{O}_{2}$ was measured using an $\mathrm{H}_{2} \mathrm{O}_{2}$ detection kit (Fluorimetric Hydrogen Peroxide Assay Kit, Sigma-Aldrich, St. Louis, MO, USA). Cells were also cultured as described above and then treated with $\mathrm{H}_{2} \mathrm{O}_{2}$ for $12 \mathrm{hr}$, followed by incubation with $10 \mu \mathrm{M}$ of $2^{\prime}, 7^{\prime}$-dichlorofluorescein diacetate (DCFH-DA) (Sigma-Aldrich, St. Louis, MO, USA) for $30 \mathrm{~min}$. Intracellular ROS level was assessed by fluorescence microscopy, and the relative mean fluorescence intensity (MFI) value was quantified by calculating fluorescence intensity within areas of individual cells using Image-Pro plus software and normalized to that measured in the PCL group. We also analyzed the expression of apoptotic and oxidative genes by real-time reverse transcription polymerase chain reaction (RT-PCR). Total RNA of hADSCs cultured on EGCGcoated PCL film was collected using TRizol reagent (Life Technologies, Carlsbad, CA, USA), and cDNA was synthesized from collected total RNA using the Maxime RT PreMix Kit (Intron Biotechnology, Gyeonggi-do, Korea). Then, the cDNA was mixed with SYBR Green PCR Mastermix (TAKARA, Otsu, Shiga, Japan), and PCR was performed in a StepOnePlus thermocycler (Life Technology, Carlsbad, CA, USA). The sequences of the primers used for RT-PCR were as follows: GAPDH (Fw: 5'-GTC AGT GGT GGA CCT GAG CT-3', Rv: 5'TGC TGT AGC CAA ATT CGT TG-3'), BAX (Fw: 5'-TTT GCT TCA GGG TTT CAT CC-3', Rv: 5'-CAG TTG AAG TTG CCG TCA GA-3'), BCL2 (Fw: 5'-GAG GAT TGT GGC CTT CTT TG-3', Rv: 5'-ACA GTT CCA CAA AGG CAT CC-3'), BCL2L1 (Fw: 5'-CTG AAT CGG AGA TGG AGA CC-3', Rv: 
5'-TGG GAT GTC AGG TCA CTG AA-3'), Catalase (Fw: 5'-GCC TGG GAC CCA ATT ATC TT-3', Rv: 5'-GAA TCT CCG CAC TTC TCC AG-3'), FOXO3 (Fw: 5'-GCA AGC ACA GAG TTG GAT GA-3', Rv: 5'-CAG GTC GTC CAT GAG GTT TT-3'), GPX-1 (Fw: 5'-CTC TTC GAG AAG TGC GAG GT-3', Rv: 5'-TCG ATG TCA ATG GTC TGG AA-3').

\subsection{Preparation and characterization of EGCG-coated PLLA fibers}

To prepare PLLA fibers, an electrospun nanofiber sheet was prepared by ejecting $10 \mathrm{ml}$ of $3 \%$ of PLLA solution dissolved in a mixture of DCM and TFE (8:2, v/v) using a syringe pump (KDS200, KD Scientific, New Hope, PA, USA) through a 23-gauge needle under $16 \mathrm{kV}$ at a rate of $2 \mathrm{ml} / \mathrm{h}$. Scattered fibers were collected on aluminum foil covered a rotating mandrel (SPG, Incheon, Korea), and the sheet was dried overnight. The nanofiber sheet was chopped into small pieces and dispersed in ethylenediamine (EDM) solution $(10 \%, v / v$ in IPA) for aminolysis. After vigorous shaking at $90 \mathrm{rpm}$ for $30 \mathrm{~min}$ at $37^{\circ} \mathrm{C}$, the aminolyzed PLLA fibers were centrifuged at 4,000 rpm for $10 \mathrm{~min}$ and washed in 70\% ethanol. $50-100 \mu \mathrm{m}$ sized PLLA fibers were collected using a sieve grid and lyophilized after 3 D.W. washes. To coat PLLA fibers (PF) with EGCG, $1 \mathrm{mg} / \mathrm{ml}$ of prepared PF (50-100 $\mu \mathrm{m})$ was dispersed in EGCG solution (100 $\mathrm{mM}$ of BIS-TRIS with $300 \mathrm{mM}$ of $\mathrm{MgCl}_{2}$ dissolved in D.W. at pH 7) and incubated for $24 \mathrm{hr}$ at $37^{\circ} \mathrm{C}$ on a rotator. The TPC on the PLLA fibers was measured by the Folin-Ciocalteu method as described in Section 2.1.

The anti-oxidative activity of EGCG-coated PLLA fibers (E-PF) was measured by a ferric reducing antioxidant power assay, ABTS radical scavenging assay, and $\mathrm{H}_{2} \mathrm{O}_{2}$ scavenging assay. PF and EPF were dispersed in D.W. $(1 \mathrm{mg} / \mathrm{ml})$ and serially diluted. $500 \mu \mathrm{l}$ of the PF sample, E-PF sample, and ascorbic acid standard were reacted with $\mathrm{Fe}(\mathrm{III})$ solution for $30 \mathrm{~min}$ and the absorbance was measured at $510 \mathrm{~nm}$. Similarly, $50 \mu \mathrm{l}$ of the PF sample, E-PF sample, and ascorbic acid standard were reacted with ABTS solution and the absorbance was measured at $732 \mathrm{~nm}$. To analyze $\mathrm{H}_{2} \mathrm{O}_{2}$ scavenging activity, PF and E-PF were dispersed in $100 \mu \mathrm{M} \mathrm{H}_{2} \mathrm{O}_{2}$ solution (0 to $1 \mathrm{mg} / \mathrm{ml}$ ), dissolved in D.W., and incubated for 2 hr at $37^{\circ} \mathrm{C}$. The remaining concentration of $\mathrm{H}_{2} \mathrm{O}_{2}$ in the solution was measured using an $\mathrm{H}_{2} \mathrm{O}_{2}$ detection kit. To evaluate the biocompatibility of PF and E-PF and hADSCs, hADSCs were cultured on a 24 -well plate at $1 \times 10^{4}$ cells $/ \mathrm{cm}^{2}$ for $24 \mathrm{hr}$. Then, the media was changed to one containing $5 \mu \mathrm{g}$ of PF or E-PF. After $24 \mathrm{hr}$ of culture, the viability of hADSCs was measured by MTT assay. The intracellular ROS level of hADSCs was measured by incubating the cells with $10 \mu \mathrm{M}$ DCFH-DA for $30 \mathrm{~min}$ after the same culture process as described above. Fluorescence intensity of individual cells was calculated by Image-Pro plus software and normalized to that of the control (-) group.

\section{5. hADSC spheroid formation with fibers and anti-oxidative effect of EGCG coated fibers on $\mathrm{H}_{2} \mathrm{O}_{2}$-treated hADSCS}

To fabricate hADSC spheroids (cells only), 40,000 hADSCs in $100 \mu \mathrm{l}$ of culture media were placed in a $0.2 \mathrm{ml}$ tube and centrifuged at 1,200 rpm for $3 \mathrm{~min}$. Cells in the tube gradually formed a spheroid during incubation for $24 \mathrm{hr}$ at $37^{\circ} \mathrm{C}$, and the spheroid was then transferred to an ultra-low attachment plate (Costar ${ }^{\circledR}$ ultra-low attachment multiple 96-well plate, Corning Incorporated, New York, USA). PF-incorporating spheroids were prepared as described above except that $10 \mu \mathrm{g}$ of PF $(1 \mu \mathrm{g} / \mu \mathrm{l})$ was added the 100 of culture medium containing 40,000 cells. Cell-only spheroids and PF-incorporating spheroids were cultured in media containing 400 $\mu \mathrm{M} \mathrm{H}_{2} \mathrm{O}_{2}$ for $12 \mathrm{hr}$. Changes in the morphology of spheroids were monitored by phase contrast microscopy and the number of deformed spheroids was quantified by image analysis and reported as a percentage. Using the same cell culture process described above, the distribution of live and dead cells in spheroids was determined by confocal microscopy (TE2000 and Eclipse C1, Nikon, Tokyo, Japan) after $30 \mathrm{~min}$ of incubation in LIVE/DEAD staining solution (Invitrogen, Carlsbad, CA, USA).

For histological analysis, $\mathrm{H}_{2} \mathrm{O}_{2}$-exposed spheroids were fixed in $4 \%$ paraformaldehyde. Fixed individual spheroids were then immersed in optimal cutting temperature compound (OCT) solution and frozen in a deep freezer $\left(-80^{\circ} \mathrm{C}\right)$ for more than $2 \mathrm{hr}$ to produce an OCT block. The frozen OCT block containing spheroids was cut into $10 \mu \mathrm{m}$ sections using a cryostat microtome and sections were collected on slide glass. To observe the internal morphology of spheroids, H\&E staining of cross-sectioned spheroids was performed. First, cross-sectioned samples were incubated twice in xylene for $10 \mathrm{~min}$. After a hydration step (rinsing with 100\% to $70 \%$ ethanol followed by running water for $10 \mathrm{~min}$ ), samples were incubated in hematoxylin for $2 \mathrm{~min}$ and eosin for $8 \mathrm{~min}$. Following dehydration, samples were preserved in mounting medium for observation. The DNA integrity of hADSCs within spheroids was determined by TUNEL assay. First, cross-sectioned samples of spheroids from the OCT block were incubated twice in xylene for $10 \mathrm{~min}$. Following hydration, samples were treated with ethanol:acetic acid $(2: 1, \mathrm{v}: \mathrm{v})$ for $5 \mathrm{~min}$. After two washes with PBS, samples were incubated in equilibration buffer for $10 \mathrm{sec}$. Then, samples were incubated with terminal deoxynucleotide transferase (TDT) for 1 hr at $37^{\circ} \mathrm{C}$. Immediately after TDT treatment, stop/wash buffer was added for $10 \mathrm{~min}$ at RT, followed by anti-digoxigenin conjugate (fluorescein) for $30 \mathrm{~min}$. Stained samples were preserved in mounting medium with DAPI. TUNEL-positive nuclei (\%) were quantified by counting the number of fluorescein-stained nuclei (positive) normalized to the total number of nuclei. In addition, spheroids exposed to $400 \mu \mathrm{M} \mathrm{H}_{2} \mathrm{O}_{2}$ for $12 \mathrm{hr}$ were incubated in $10 \mu \mathrm{M}$ DCFH-DA for $30 \mathrm{~min}$, and then intracellular ROS levels were quantified by fluorescence microscopy. Relative MFI was quantified by calculating the fluorescence intensity of individual spheroids and normalizing this to that of cell-only spheroids. For apoptotic and oxidative gene expression analyses, spheroids exposed to $\mathrm{H}_{2} \mathrm{O}_{2}$ were immersed in TRizol reagent, and were then broken apart by pipetting several times to extract RNA. Subsequent steps for RTPCR were the same as those described in Section 2.3.

\subsection{Statistics and analyses}

Quantitative data are presented as means \pm standard deviations. One-way analysis of variance (ANOVA) using Tukey's honestly significant difference test and two-way ANOVA (for two variables) using the Bonferroni post-test were performed using GraphPad Prism 5 software (La Jolla, CA, USA). A $p$ value $<0.05$ was considered to denote statistical significance.

\section{Results and discussion}

\subsection{Characterization of EGCG-coated PCL films}

The overall scheme of EGCG coating on a biomaterial surface through MPN formation and the potential effects on 2D, 3D cultured cell underlying its anti-oxidative activity are illustrated in Fig. 1. According to the EGCG coating, the white color PCL surface turned slightly brown in $\mathrm{Na}-\mathrm{E}$ and $\mathrm{Mg}-\mathrm{E}$, and small aggregates were observed in Mg-E (Supplementary Fig. S1). The TPC on the PCL film increased significantly in the presence of cations, with $\mathrm{Mg}^{2+}$ increasing TPC on the PCL firm to a greater extent than $\mathrm{Na}^{+}$(17 $\pm 3 \mu \mathrm{g} / \mathrm{cm}^{2}$ vs $8 \pm 1 \mu \mathrm{g} / \mathrm{cm}^{2}$, respectively) (Fig. 2a). When various types of metal ions were used for EGCG coating, TPC from divalent was significantly greater than that from monovalent ions while no significant difference was found in different ions of each group (Supplementary Fig. S2). The TPC on PCL film 


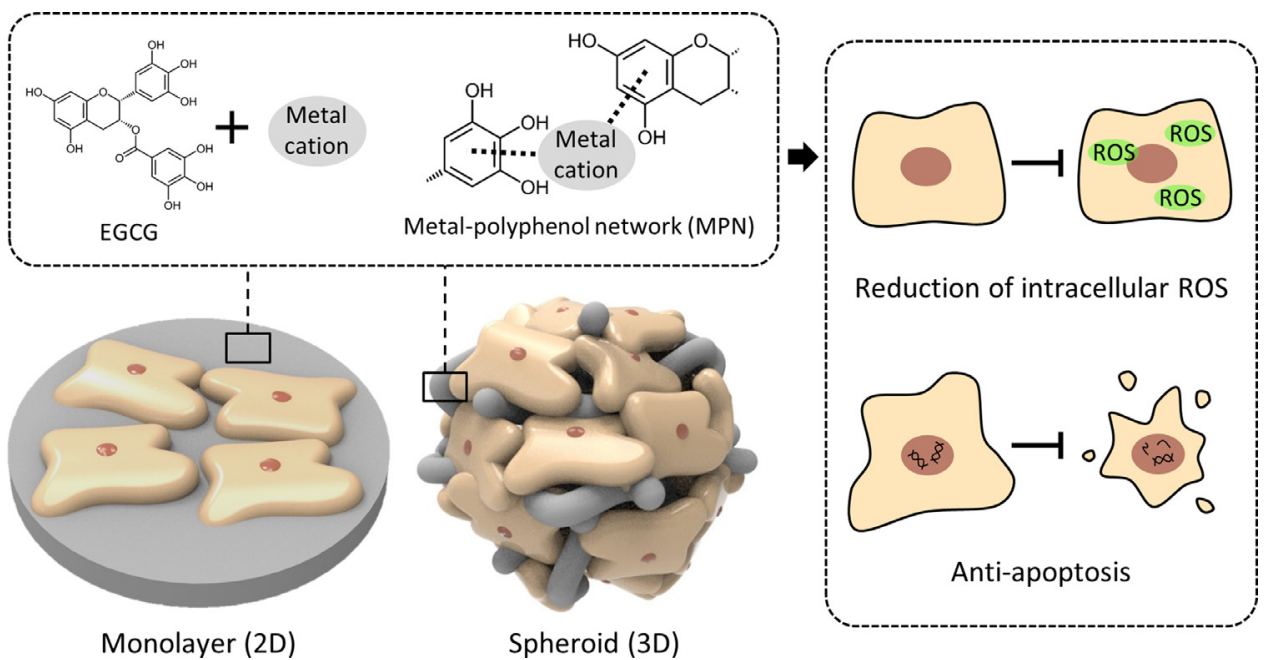

Fig. 1. Schematic diagram of the anti-oxidative properties of EGCG coating to reduce intracellular ROS and anti-apoptosis on 2D, 3D cultured cells.

(a)

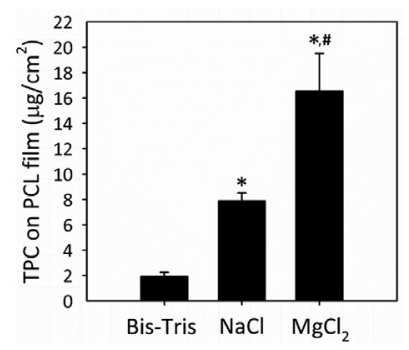

(d)

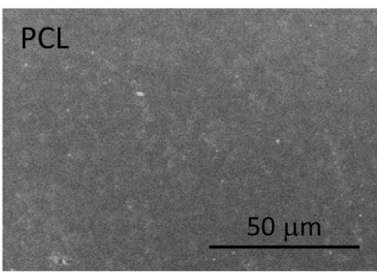

(e)

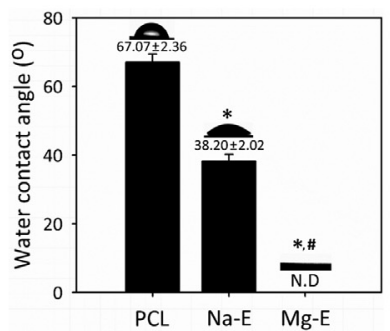

(b)
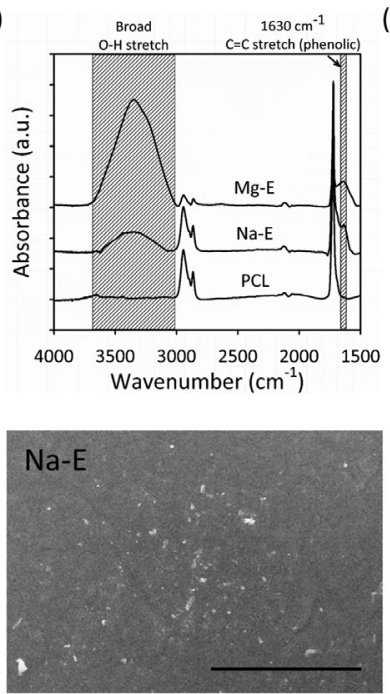

(f)

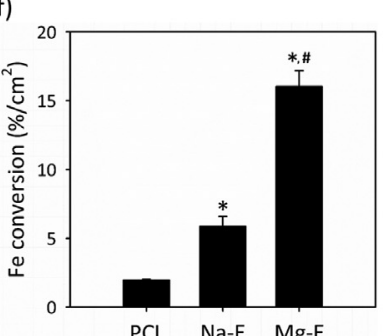

(c)
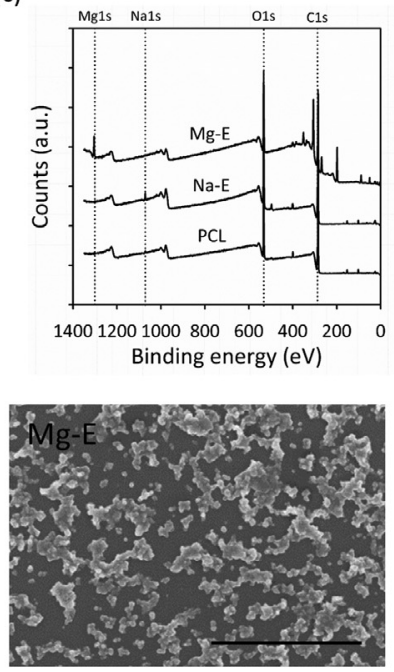

(g)

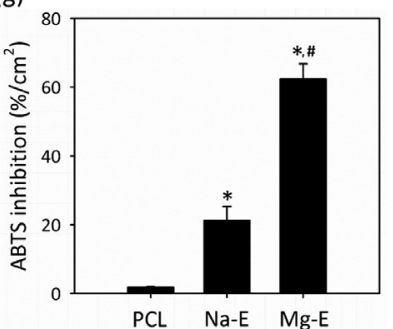

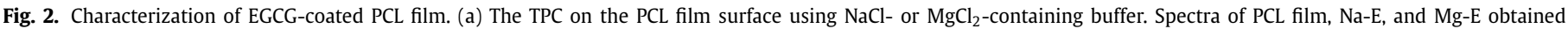

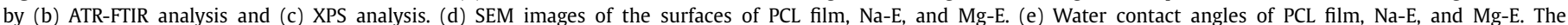
anti-oxidative activity of EGCG-coated PCL film as measured by (f) ferric reducing antioxidant power assay and (g) ABTS radical scavenging assay (*, \# p < 0.05 ).

surface remained $80 \%$ and $60 \%$ in $\mathrm{Na}-\mathrm{E}\left(6 \pm 1 \mu \mathrm{g} / \mathrm{cm}^{2}\right)$ and $\mathrm{Mg}$ $\mathrm{E}\left(10 \pm 1 \mu \mathrm{g} / \mathrm{cm}^{2}\right)$ for 7 days (Supplementary Fig. S3). ATR-FTIR results demonstrated that a broad $\mathrm{O}-\mathrm{H}$ stretch at $3000-3700 \mathrm{~cm}^{-2}$ and phenolic $\mathrm{C}=\mathrm{C}$ stretch at $1630 \mathrm{~cm}^{-1}$ were present after coating with EGCG (Fig. 2b), indicating successful coating with EGCG. These results are consistent with a previous report [26]. In addition, specific peaks of Na1s and Mg1s were detected by XPS analysis on the surface of $\mathrm{Na}-\mathrm{E}$ and $\mathrm{Mg}-\mathrm{E}$, respectively (Fig. 2c). In the XPS C1s high-resolution spectra, peak intensity of $\mathrm{C}-\mathrm{O}$ bonding $(286.4 \mathrm{eV})$ was elevated in $\mathrm{Na}-\mathrm{E}$ and more in $\mathrm{Mg}-\mathrm{E}$ than PCL (Supplementary Fig. S4). SEM results showed that bare PCL had a smooth surface while agglomerated particles were found on the Mg-E surface (Fig. 2d). Following EGCG coating, bare PCL film (67 $\pm 2^{\circ}$ ) became hydrophilic and complete wetting was observed on the PCL surface coated with the greater TPC (Fig. 2e). As shown in Fig. $2 \mathrm{f}$ and $\mathrm{g}$, the conversion ratio of $\mathrm{Fe}\left(\% / \mathrm{cm}^{2}\right)$ was significantly elevated after EGCG coating as compared to bare PCL $\left(2 \pm 0 \% / \mathrm{cm}^{2}\right)$, and $\mathrm{Mg}-\mathrm{E}\left(16 \pm 1 \% / \mathrm{cm}^{2}\right)$ had a significantly greater Fe conversion ratio than $\mathrm{Na}-\mathrm{E}\left(6 \pm 1 \% / \mathrm{cm}^{2}\right)$. Similarly, Mg-E inhibited ABTS radicals significantly more than bare PCL and Na-E (Fig. 2g).

The divalent cation $\mathrm{Mg}^{2+}$ led to a greater level of MPN-based coating than the monovalent cation $\mathrm{Na}^{+}$. MPN is the supramolec- 
ular network structure, in which metal ions are coordinated to phenolic ligands with $\pi$-cation interactions playing a crucial role $[19,27]$. In a previous study, no catechin (CA) coating was formed on a PCL nanofiber surface in the absence of sodium ion $\left(\mathrm{Na}^{+}\right)$ [28]. Similar to our findings, more pyrogallol (PG) coating was achieved on the titanium surface with magnesium ion $\left(\mathrm{Mg}^{2+}\right)$ than $\mathrm{Na}^{+}$[29]. In the XPS C1s high-resolution results, the gradual improvement in $\mathrm{C}-\mathrm{O}$ bonding in $\mathrm{Na}-\mathrm{E}$ and $\mathrm{Mg}-\mathrm{E}$ than in $\mathrm{PCL}$ can be estimated by the improvement of phenolic C-O contents due to the increase in TPC of the surface. The structure of MPN with non-covalent interactions between metal ions and phenolic molecules has been indirectly estimated by stoichiometry and XPS analysis [19,30]. For example, mono/bis/tris-complex was estimated through the relative ratio of $\mathrm{Fe}^{3+}$ and $\mathrm{TA}$, and the peak shift to higher binding energy through XPS analysis would have caused electron transfer from TA to Fe ions. In our results, the increased phenolic $\mathrm{C}-\mathrm{O}$ content indirectly shows that $\mathrm{Mg}^{2+}$ can form more MPN than $\mathrm{Na}^{+}$. SEM analysis consistently supported more coating with $\mathrm{Mg}^{2+}$ than $\mathrm{Na}^{+}$. The formation of small aggregates was reported during polyphenol coating when coating exceeded a certain level [29]. The surface hydrophilicity increased with increase in TPC, indicating that the -OH groups of catechin and gallol in EGCG after coating may have contributed to the formation of hydrogen bonds with $\mathrm{H}_{2} \mathrm{O}$ on the surface and the increased hydrophilicity. Consistently, the Mg-E surface exhibited 2-3-fold greater Fe conversion/ABTS scavenging activity than $\mathrm{Na}$-E surface, suggesting that phenolic contents on the surface appear to be responsible for antioxidant activity to reduce $\mathrm{Fe}\left(\mathrm{Fe}^{3+} \rightarrow \mathrm{Fe}^{2+}\right)$ and to scavenge radicals [31]. It has been reported that the hydroxyl groups in phenolic ring structure of EGCG can scavenge radicals and chelate metal ion during self-oxidation, and the electron transfer in phenolic $\pi$ electrons is dependent on the amount of EGCG coated on the surface of the substrate [32].

\subsection{Adhesion of hADSCS and ROS scavenging activity of EGCG-coated PCL films}

To confirm the viability of hADSCs after EGCG treatment, cells were observed after LIVE/DEAD staining and cellular metabolic activity was quantified by MTT assay (Fig. 3a and b). Cell morphology and viability were not significantly affected by EGCG treatment. EGCG has been reported to be cytotoxic to mesenchymal cells only at concentration higher than $50 \mu \mathrm{M}$ [33]. Consistent with this previous study, EGCG at concentrations lower that $50 \mu \mathrm{M}$ was not cytotoxic to hADSCs. The number of attached cells on films cultured for $24 \mathrm{hr}$ was significantly greater on the EGCG-coated surfaces (Na-E, $177 \pm 21 / \mathrm{mm}^{2}$ and $\mathrm{Mg}$-E, $128 \pm 7 / \mathrm{mm}^{2}$ ) than on the PCL film $\left(87 \pm 20 / \mathrm{mm}^{2}\right)$ (Fig. 3c). In addition, hADSCs became narrower and thinner (spreading area $5.2 \pm 1.610^{3} \mu^{2}$ per cell) on the PCL film, while they had a more broad polygonal shape on Na-E and Mg-E films (spreading area $9.0 \pm 3.510^{3}$ $\mu \mathrm{m}^{2}$ and $7.3 \pm 1.510^{3} \mu \mathrm{m}^{2}$ per cell, respectively) (Fig. $3 \mathrm{~d}$ and e). According to previous reports, surface characteristics such as hydrophilicity and roughness are altered by polyphenol coating, and cell attachment and spreading area change accordingly. For example, the $\mathrm{Fe}^{3+} / \mathrm{TA}$ coated surface of PCL nanofiber mesh became hydrophilic and small aggregates formed on the surface, similar to our findings [34]. Furthermore, human umbilical vein endothelial cells (HUVECs) cultured on PCL nanofiber mesh showed greater adhesion and spreading than HUVECs cultured on uncoated PCL nanofibers [34]. The reduced number of adherent cells on the MgE surface may be due to the roughness of the Mg-E surface. It has been reported that the adhesion force of cells decreases as surface roughness increases above a certain level (adhesion inhibition) [35].
Viability of hADSCs after $\mathrm{H}_{2} \mathrm{O}_{2}$ treatment decreased significantly as the concentration of $\mathrm{H}_{2} \mathrm{O}_{2}$ increased and exposure time increased (Fig. 4a). For example, after $24 \mathrm{hr}$, the viability of hADSCs decreased from $83 \pm 2 \%$ at $200 \mu \mathrm{M} \mathrm{H}_{2} \mathrm{O}_{2}$ to $11 \pm 0 \%$ at $400 \mu \mathrm{M}$ $\mathrm{H}_{2} \mathrm{O}_{2}$ compared to the control. However, when cells were treated with both $\mathrm{H}_{2} \mathrm{O}_{2}$ and EGCG $(0,12.5,25,50 \mu \mathrm{M})$, the viability of hADSCs after $24 \mathrm{hr}$ improved significantly (by 10-20\%) as compared to that without EGCG (74 $\pm 5 \%$ ) (Fig. $4 \mathrm{~b}$ ). Changes in the morphology of hADSCs cultured on PCL film and EGCG-coated PCL film were observed after $12 \mathrm{hr}$ of exposure to $200 \mu \mathrm{M} \mathrm{H}_{2} \mathrm{O}_{2}$. Cells cultured on PCL film were shrunken and had a low spread area (3 $\pm 210^{3} \mu \mathrm{m}^{2}$ per cell) while cells cultured on Na-E and Mg-E exhibited an increased spread area relative to cells cultured on PCL film (12 $\pm 310^{3} \mu \mathrm{m}^{2}$ and $11 \pm 310^{3} \mu \mathrm{m}^{2}$ per cell, respectively) (Fig. 4c and d).

EGCG treatment protected hADSCs against $\mathrm{H}_{2} \mathrm{O}_{2}$ mediated-ROS damage, consistent with a previous study that reported that $75 \%$ of hMSCs treated with $200 \mu \mathrm{M}$ of $\mathrm{H}_{2} \mathrm{O}_{2}$ for $24 \mathrm{hr}$ were senescent based on $\beta$-galactosidase staining whereas pre-treatment of hMSCs with $50 \mu \mathrm{M}$ EGCG for $6 \mathrm{hr}$ reduced senescence to 50\% [36]. Control of oxidative stress generated during biomaterial transplantation or cell transplantation is important, and several studies have confirmed that tissue regeneration improves when antioxidants are used [37,38]. For example, silk fibroin nanofibers incorporating the antioxidant fenugreek (1:1) had 67\% DPPH radical scavenging effect after $24 \mathrm{hr}$ and improved wound healing in a rat full thickness excision model as compared to control and silk fibroin only [39]. In addition, anti-oxidative polyorganophosphazene (PATGP) microspheres fabricated using aniline tetramers and glycine ethyl ester co-substitution showed more than twice the $\mathrm{DPPH}, \cdot \mathrm{OH}$ scavenging activity and bone regeneration activity in a rat calvarial defect model after 8 and 16 weeks compared to PLGA and PAGP microspheres [40]. We found that the spread area of hADSCs cultured on Na-E and Mg-E surfaces was significantly greater than that on PCL film. $\mathrm{H}_{2} \mathrm{O}_{2}$ can form highly reactive hydroxyl radicals either spontaneously or through a fenton reaction that causes oxidation, which directly attacks the cell walls (lipids) and DNA of hADSCs [41]. Therefore, it can be interpreted that the reduced spread area of damaged hADSCs may be due to the contraction of apoptotic cells, whereas cell adhesion and spread area was improved on EGCG-coated PCL film due to protective effect by ROS scavenging properties of EGCG. Phenols can react with the free radical species to delocalize unpaired electrons within the aromatic ring, giving phenol radicals that undergo resonance-stabilization within the molecule and thus, form stable intermediates [42]. $\mathrm{H}_{2} \mathrm{O}_{2}$ is a non-radical oxidizing agent that can decompose in physiological conditions to form highly reactive hydroxyl radicals $(\cdot \mathrm{OH})[43,44]$. The hydroxyl radicals cause cytotoxicity, and the resonance-stabilization by the aromatic ring of phenol can remove this hydroxyl radicals by aforementioned resonancestabilization [42]. Given that, the delocalization of unpaired electrons within the phenolic structure of MPN coated on the surface may have removed cytotoxic hydroxyl radicals and produced stable $\mathrm{H}_{2} \mathrm{O}$ and $\mathrm{O}_{2}$, improving cell viability.

\subsection{Anti-apoptotic and anti-oxidative activities of EGCG-coated PCL film against $\mathrm{H}_{2} \mathrm{O}_{2}$}

$\mathrm{H}_{2} \mathrm{O}_{2}$ treatment did not change the number of cells attached to the surfaces of $\mathrm{Na}-\mathrm{E}$ and $\mathrm{Mg}-\mathrm{E}$, while it significantly decreased the number of cells attached to bare PCL film (Fig. 5b). In addition, the percentage of TUNEL-positive nuclei (\%) was significantly greater for cells attached to PCL $(75 \pm 7 \%)$ than Na-E (35 $\pm 12 \%)$ and $\mathrm{Mg}-\mathrm{E}(10 \pm 10 \%)$ (Fig. $5 \mathrm{a}$ and $\mathrm{c}$ ). $\mathrm{H}_{2} \mathrm{O}_{2}$ causes apoptotic DNA fragmentation, and EGCG has been shown to reduce the damage caused by $\mathrm{H}_{2} \mathrm{O}_{2}$. For example, treatment of pancreatic alpha TC1-6 
(a)

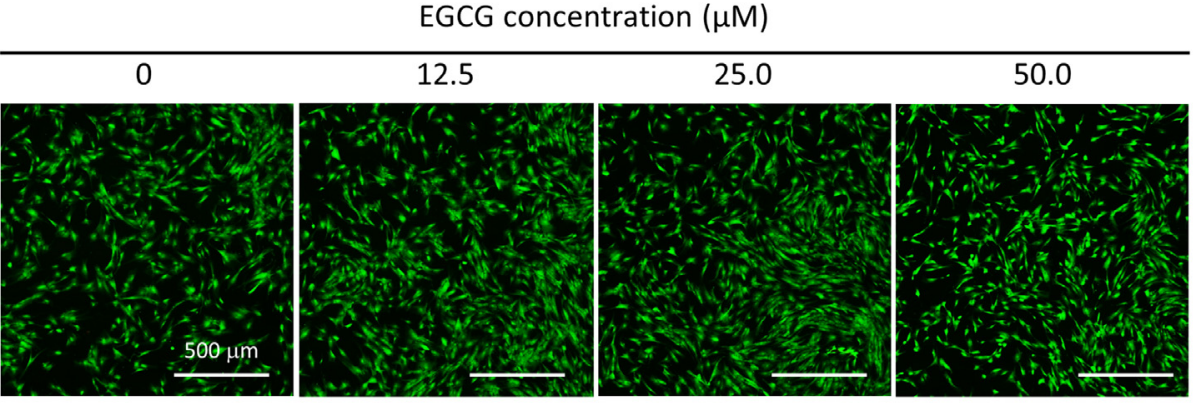

(b)

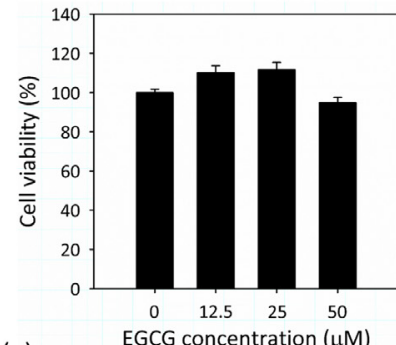

(e)

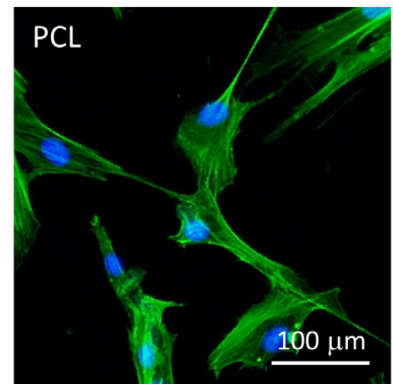

(c)
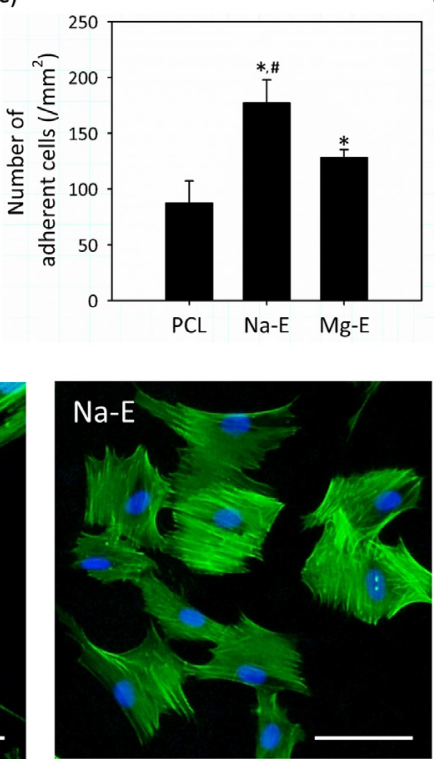

(d)
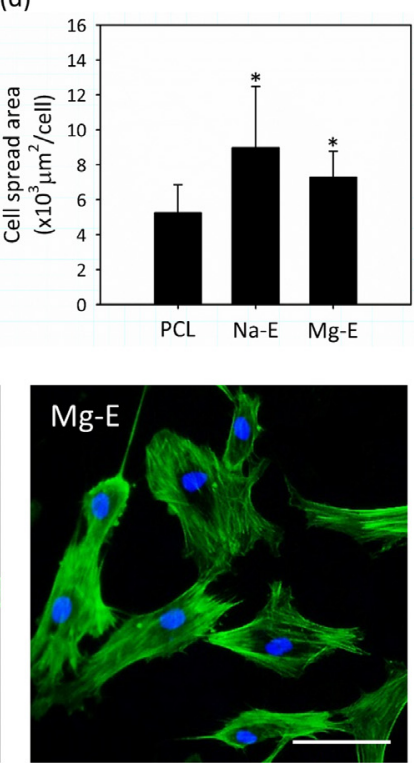

Fig. 3. EGCG cytotoxicity and attachment of hADSCs to PCL film. (a) LIVE/DEAD staining of hADSCs after $24 \mathrm{hr}$ of EGCG treatment $(0,12.5,25,50 \mu \mathrm{M})$ and (b) MTT assay results. (c) The number of hADSCs attached to PCL, Na-E, and Mg-E after 1 day of culture. After F-actin staining, (d) cell spread area and (e) fluorescence were quantified (*, $\# \mathrm{p}<0.05)$.

(a)

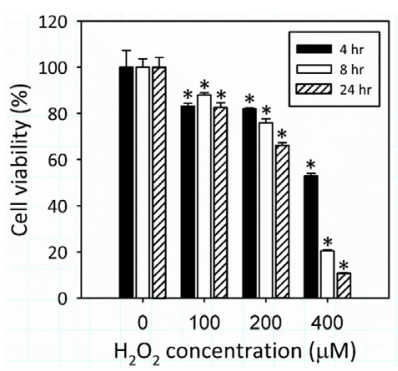

(d)

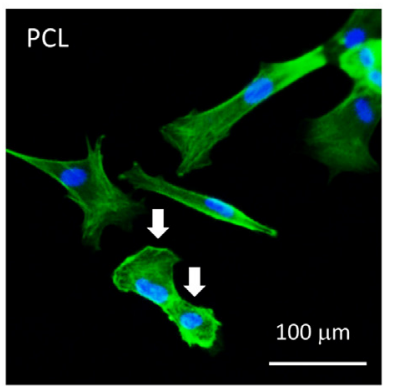

(b)
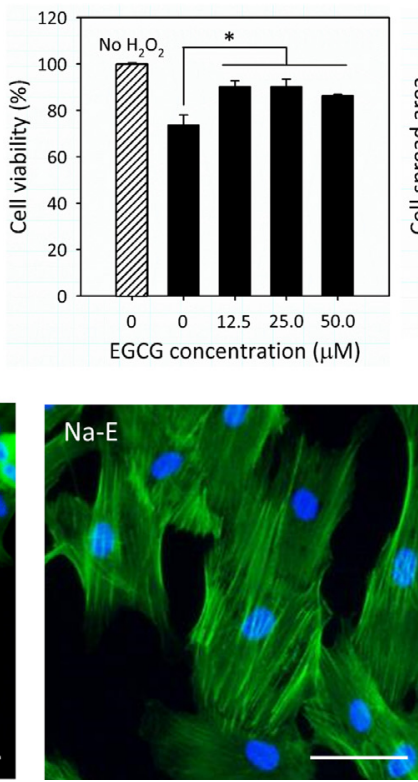

(c)
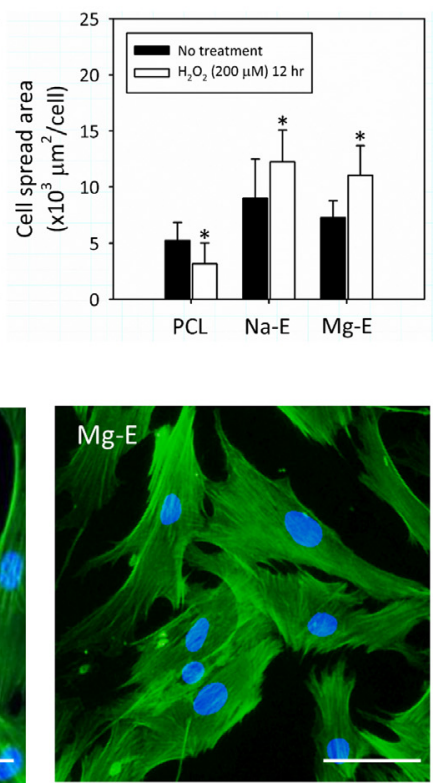

Fig. 4. Viability and morphological change of hADSCs after $\mathrm{H}_{2} \mathrm{O}_{2}$ treatment. (a) Viability of hADSCs after treatment with $0,100,200$, or $400 \mu \mathrm{M} \mathrm{H}_{2} \mathrm{O}_{2}$ for 4,8 , and 24 hr. (b) Viability of hADSCs after 1 day of culture with $200 \mu \mathrm{M} \mathrm{H} \mathrm{O}_{2}+$ EGCG $(0,12.5,25,50 \mu \mathrm{M})$. After $12 \mathrm{hr}$ of $200 \mu \mathrm{M} \mathrm{H}_{2} \mathrm{O}_{2}$ treatment of hADSCs cultured for 1 day on the PCL film surface, changes in (c) cell spread area and (d) fluorescence were quantified $\left({ }^{*}, \# \mathrm{p}<0.05\right)$. 
(a)
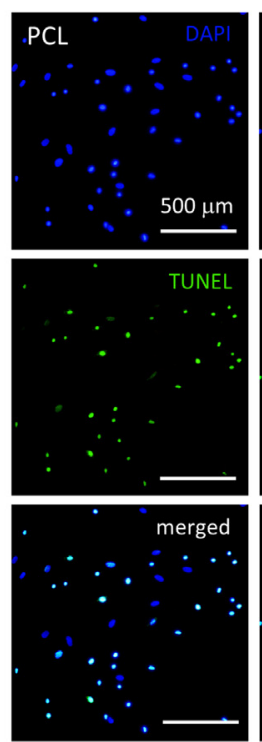

(d)

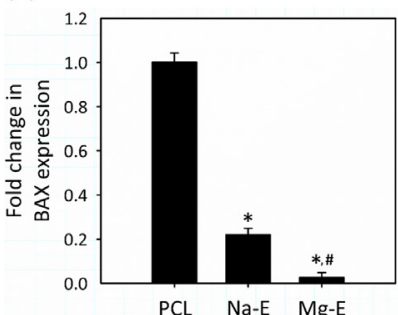

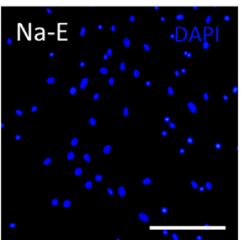
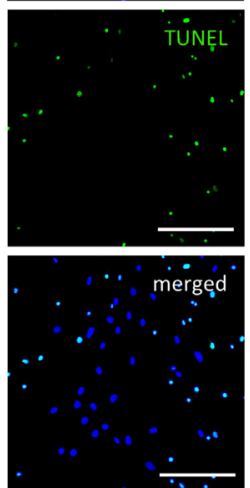

(e)
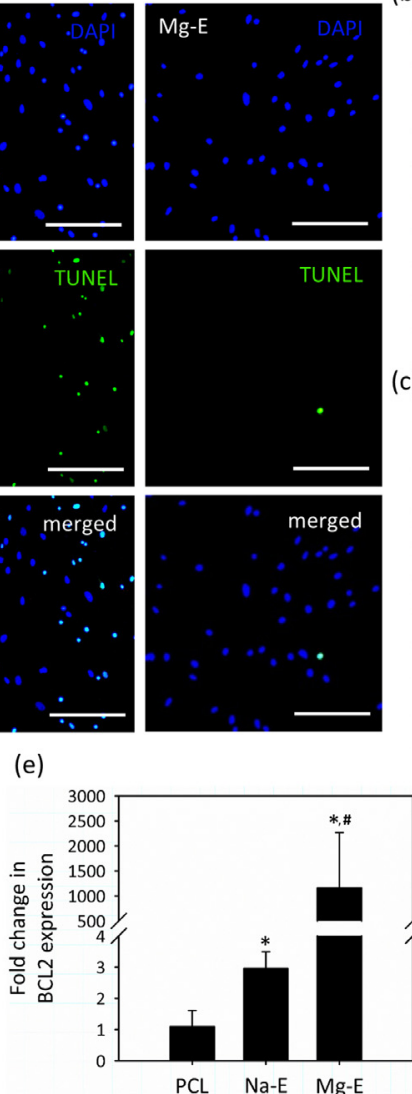

(b)

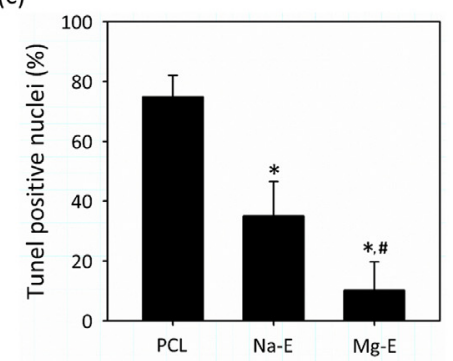

(f)

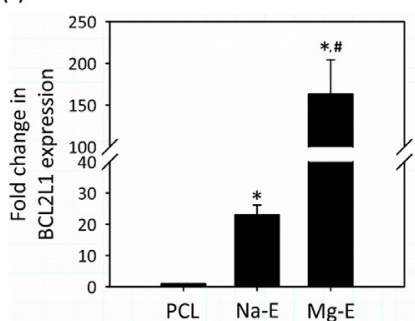

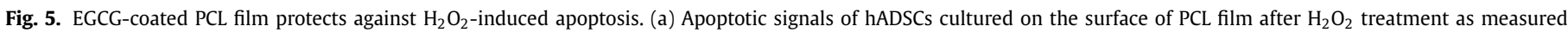

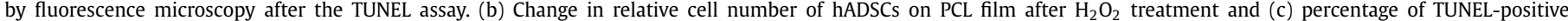
nuclei. Relative expression of the apoptosis-related genes (d) BAX, (e) BCL2, and (f) BCL2L1 in hADSCs $(*$, \# p $<0.05$ ).

cells for $4 \mathrm{hr}$ with $100 \mu \mathrm{M} \mathrm{H} \mathrm{O}_{2}$ resulted in 90\% TUNEL-positive nuclei, which was reduced to $70 \%$ and $5 \%$ after $1 \mathrm{~h}$ pre-treatment with EGCG $30 \mu \mathrm{M}$ and $100 \mu \mathrm{M}$, respectively [45]. Our results suggest that EGCG coated on the polymer surface was also able to protect against $\mathrm{H}_{2} \mathrm{O}_{2}$-induced apoptosis in a dose-dependent manner. The expression of the apoptotic gene BAX in cultured hADSCs was significantly decreased in cells cultured on Na-E and Mg-E relative to bare PCL film, with the greatest decrease in expression of this gene observed for cells cultured on Mg-E (Fig. 5d). Expression of the anti-apoptotic genes BCL2 and BCL2L1 was significantly increased in $\mathrm{Na}-\mathrm{E}$ and $\mathrm{Mg}-\mathrm{E}$ with the highest expression observed for cells grown on Mg-E compared to bare PCL film (Fig. 5e and f). EGCG has previously been reported to have a modulatory effect on the expression of apoptosis-related genes; mouse vascular smooth muscle cells cultured in a conditioned environment with $\mathrm{H}_{2} \mathrm{O}_{2}$ showed significantly reduced expression of the pro-apoptotic genes caspase-3,8,9 and BAX and a significant increase in the expression of the anti-apoptotic gene BCL-2 after pre-treatment with EGCG [46]. Our results confirmed that the EGCG coating on the surface of PCL film was biologically active and influenced anti-oxidative signaling processes within hADSCs cultured on EGCG-coated film.

To investigate the $\mathrm{H}_{2} \mathrm{O}_{2}$ scavenging activity of the EGCG coating, PCL film and EGCG-coated PCL film were incubated in $100 \mu \mathrm{M}$ $\mathrm{H}_{2} \mathrm{O}_{2}$ solution for $2 \mathrm{hr} . \mathrm{H}_{2} \mathrm{O}_{2}$ level was not reduced by the uncoated PCL film while levels of $\mathrm{H}_{2} \mathrm{O}_{2}$ were significantly decreased in solutions containing Na-E and Mg-E film to $97 \pm 1 \%$ and $87 \pm$ $2 \%$ of control levels, respectively (Fig. 6a). The relative MFI per cell in the DCFH-DA assay was significantly lower for cells cultured on Na-E and Mg-E film at $43 \pm 10 \%$ and $24 \pm 5 \%$ of the MIF per cell observed for cells cultured on PCL film (Fig. 6b). Fluorescence microscopy revealed that hADSCs cultured on PCL film without $\mathrm{H}_{2} \mathrm{O}_{2}$ showed little fluorescence signal (Fig. $6 \mathrm{c}$ ), while there was a significant increase in fluorescence signal after $\mathrm{H}_{2} \mathrm{O}_{2}$ treatment (Fig. 6d). In addition, fluorescence intensity was reduced in $\mathrm{Na}-\mathrm{E}$ and $\mathrm{Mg}-\mathrm{E}$ compared to PCL film (Fig. 6d). The expression of catalase, FOXO3, and GPX-1 was significantly increased in cells cultured on Na-E and highest for cells cultured on Mg-E compared to cells cultured on bare PCL film (Fig. 6e, f, and g). Polyphenols have been reported to eliminate $\mathrm{H}_{2} \mathrm{O}_{2}$ and related ROS. For example, real-time $\mathrm{H}_{2} \mathrm{O}_{2}$ monitoring of a skin membrane-covered oxygen electrode ( $\mathrm{SCOE}$ ) revealed that $1 \mathrm{mM} \mathrm{H} \mathrm{H}_{2} \mathrm{O}_{2}$ was rapidly reduced after treatment with $0.1 \mathrm{mM}$ polyphenols such as hydroquinone, quercetin, piceatannol, and resveratrol [47]. As described in Section 3.2, EGCG is expected to be able to remove $\mathrm{H}_{2} \mathrm{O}_{2}$ by resonance-stabilization mechanism, and our results suggest that EGCG retained its phenolic structure after coating. Furthermore, the EGCG coating appeared not only to remove ROS through direct anti-oxidative processes and resonance-stabilization, but also to regulate anti-oxidative enzyme expression in proportion to the TPC deposited on the film.

\subsection{Characterization of EGCG-coated PLLA fibers}

We next investigated the anti-oxidative protective effects of an EGCG coating on 3D spheroidal cultures of stem cells by preparing EGCG-coated PLLA fibers. According to the EGCG coating, the white color of PF turned brown in E-PF (Supplementary Fig. S5). SEM photographs (Fig. 7a) demonstrated that the smooth surfaces of PF became rough after coating with $48 \pm 2 \mu \mathrm{g} / \mathrm{mg}$ EGCG, indicating 
(a)

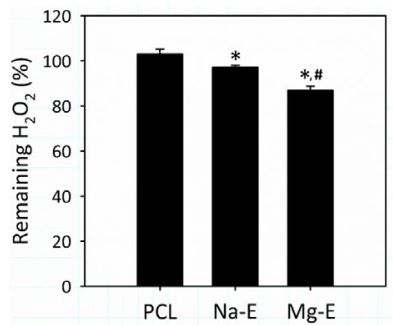

(b)

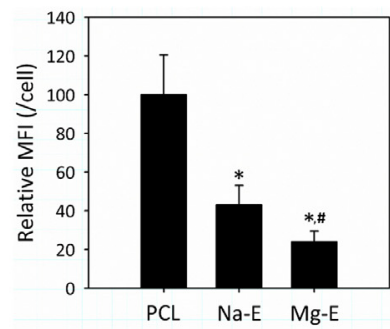

(c)

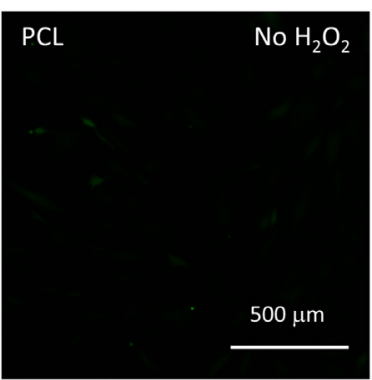

(d)

$\mathrm{H}_{2} \mathrm{O}_{2}(200 \mu \mathrm{M}) 12 \mathrm{hr}$
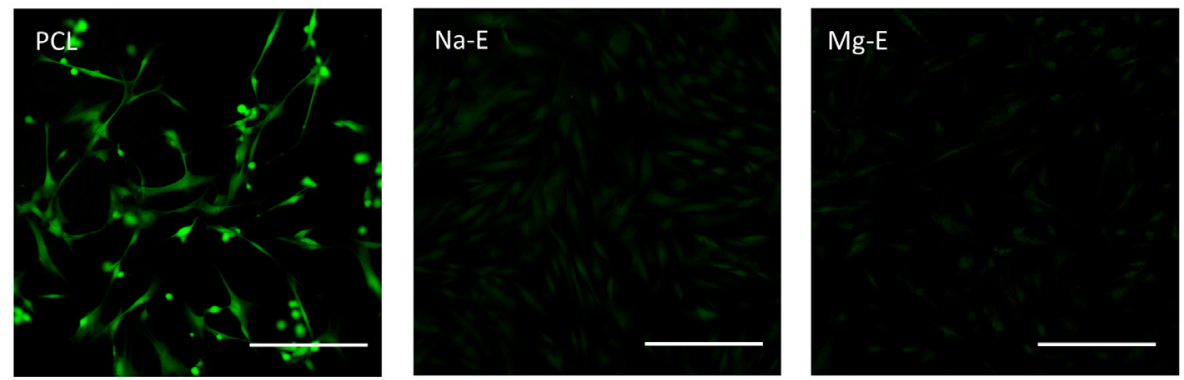

(e)

(f)

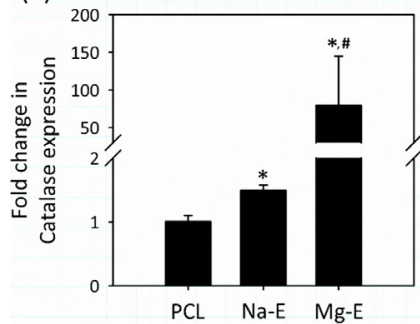

(g)
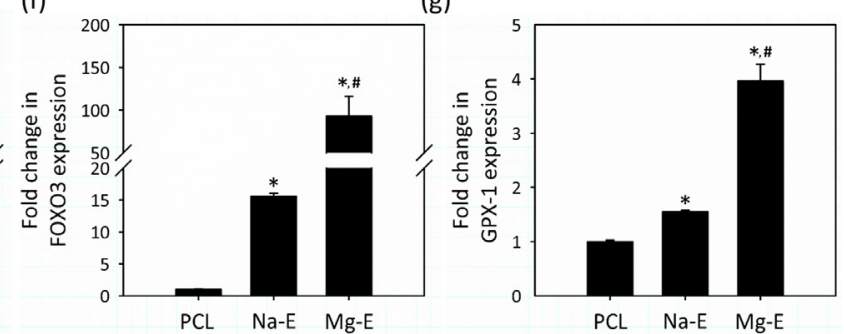

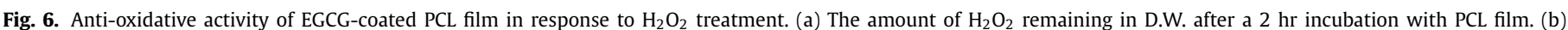

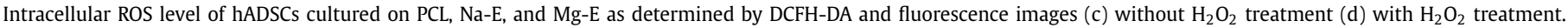
Relative expression of anti-oxidative genes (e) catalase, (f) FOXO3, and (g) GPX-1 in hADSCs (*, \# p < 0.05).

homogeneous deposition of EGCG (Fig. 7b). Ferric reducing activity [conversion rate (\%)] increased up to $28 \pm 5 \%$ as the percentage of fibers increased (Fig. 7c). Similarly, E-PF showed ABTS radical scavenging activity that increased in proportion to the amount of fibers, as shown in Fig. $7 \mathrm{~d}$. In an aqueous environment containing $\mathrm{H}_{2} \mathrm{O}_{2}$, E-PF effectively reduced $\mathrm{H}_{2} \mathrm{O}_{2}$ and thus decreased the amount of $\mathrm{H}_{2} \mathrm{O}_{2}$ significantly $(85 \pm 2 \%$ ) as a function of fiber concentration (Fig. 7e). EGCG-coated fibers had no detrimental effect on cell viability (Fig. 7f). Intracellular ROS level (relative MFI) increased rapidly in the positive control $(143 \pm 17)$ treated with $\mathrm{H}_{2} \mathrm{O}_{2}$ compared to the negative control $(100 \pm 1)$ without $\mathrm{H}_{2} \mathrm{O}_{2}$ treatment. In the PF-treated group, fluorescence intensity per individual cell was not statistically different than that in the positive control $(140 \pm 8)$, but was significantly decreased in the E-PF treated group $(110 \pm 4)$ (Fig. $7 \mathrm{~g}$ and $\mathrm{h}$ ).

The aforementioned results suggest that EGCG directly removes ROS through phenolic $\pi$-electron and resonance-stabilization of catechin and gallol groups, and/or stimulates anti-apoptotic and anti-oxidative cell signaling pathways. Similarly, EGCG-coated fibers exhibited anti-oxidative properties as confirmed by Fe conversion, ABTS radical scavenging, and elimination of $\mathrm{H}_{2} \mathrm{O}_{2}$, indicating maintenance of the biological activity of EGCG independent of the surface chemistry of the underlying materials. In addition, EPF effectively reduced the intracellular ROS level of hADSCs cultured on tissue culture plates. It has been reported that the level of intracellular ROS is indicative of cellular damage. For example, the greater the intracellular ROS level of primary cardiac stem cells and embryonic stem cells, the more DNA damage was found [48]. The antioxidant curcumin $(0-4 \mu \mathrm{M})$ concentration-dependently decreased the DCF fluorescence intensity of L-6 myoblasts [49], while the antioxidant edaravone decreased the intracellular ROS level of human umbilical cord mesenchymal stem cells [11], indicating that these antioxidants can decrease the level of intracellular ROS. However, directly delivered soluble antioxidants were rapidly eliminated (8-90\% removed within $24 \mathrm{hr}$ ) and showed decreased antioxidative activity in vivo [12]. Our results indicate coating the surfaces of biomaterials with EGCG can effectively remove ROS and potentially protect tissues against oxidative damage. It is known that soluble EGCG exhibits anti-oxidative properties in proportion to the concentration, but its use has been very limited in tissue engineering applications due to potential cytotoxicity at concentrations above $50 \mu \mathrm{M}[33,50]$. When EGCG was coated on biomaterial, EGCG can be stably coated on the surface via MPN formation and could be maintained for a long time without cytotoxicity.

\subsection{Spheroid formation with EGCG-fibers and their ability to protect} hADSCs within the spheroids against $\mathrm{H}_{2} \mathrm{O}_{2}$

We next fabricated PLLA fibers for incorporation in stem cells spheroids and investigated their effects on 3D cultured stem cells. Similar to the aforementioned experiments, spheroids were exposed to $400 \mu \mathrm{M} \mathrm{H}_{2} \mathrm{O}_{2}$ for $12 \mathrm{hr}$. Structural deformation was ob- 
(a)

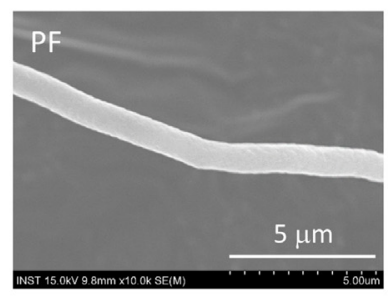

(c)

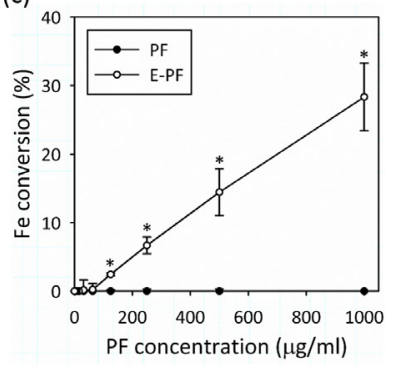

(f)

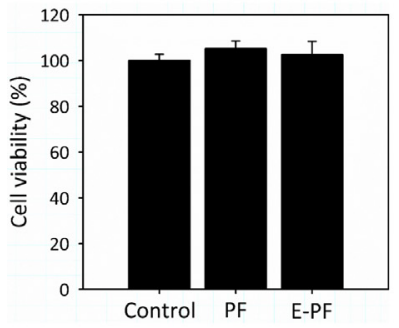

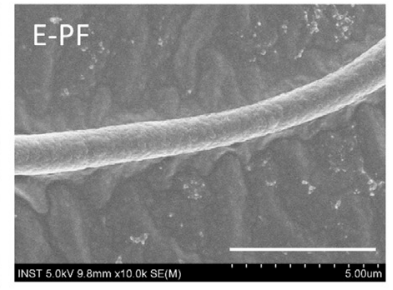

(d)

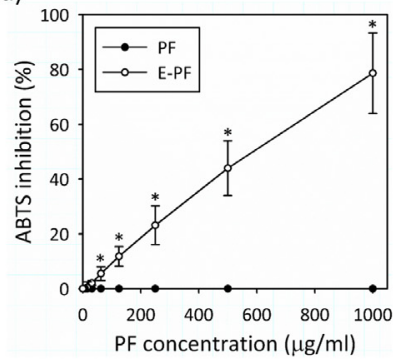

(g)

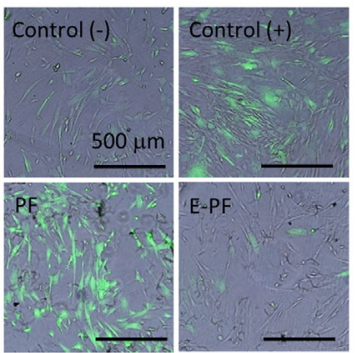

(b)

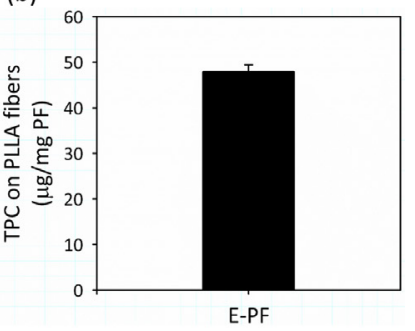

(e)

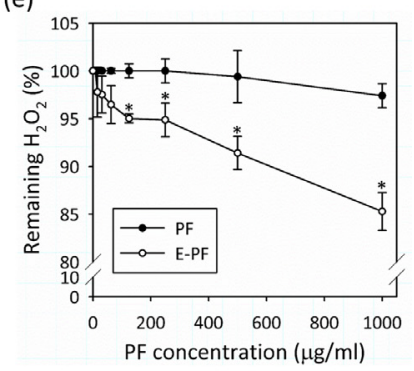

(h)

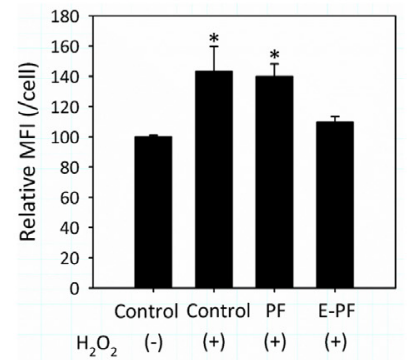

Fig. 7. Characterization of PLLA fibers (PF) and EGCG-coated PLLA fibers (E-PF). (a) SEM image of PF and E-PF surfaces. (b) The TPC on E-PF. The anti-oxidative activity of PF and E-PF was measured by (c) ferric reducing antioxidant power assay, and (d) ABTS radical scavenging assay. (e) The amount of $\mathrm{H}_{2} \mathrm{O}_{2}$ remaining after incubation of PF and E-PF in $100 \mu \mathrm{M}$ of $\mathrm{H}_{2} \mathrm{O}_{2}$ in D.W. for $2 \mathrm{hr}$. (f) Viability of hADSCs cultured with PF or E-PF for one day. (g) Fluorescence images of intracellular ROS in hADSCs cultured with PF or E-PF in the presence of $\mathrm{H}_{2} \mathrm{O}_{2}$ for 1 day and (h) relative MFI per individual cell based on the DCFH-DA assay $\left({ }^{*} \mathrm{p}<0.05\right)$.

(a)
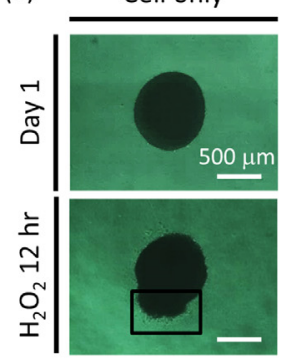

(c)

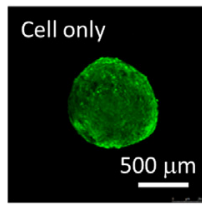

(d)

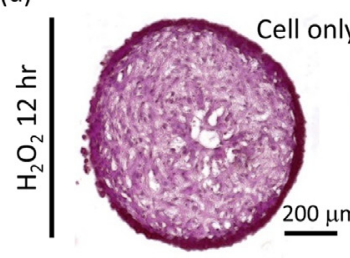

PF
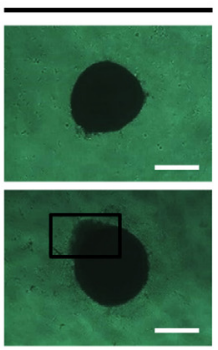

E-PF

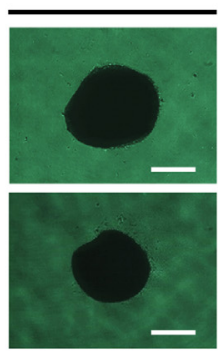

(b)

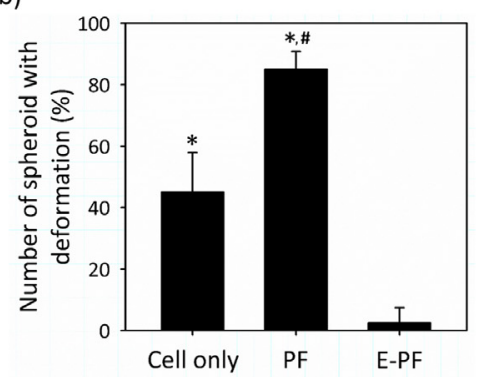

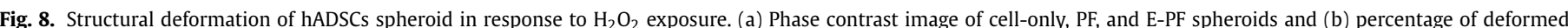

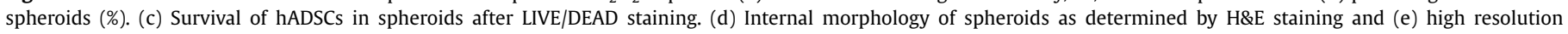
imaging of PF-incorporating spheroids $\left({ }^{*}\right.$, \# $\left.\mathrm{p}<0.05\right)$. 
(a)
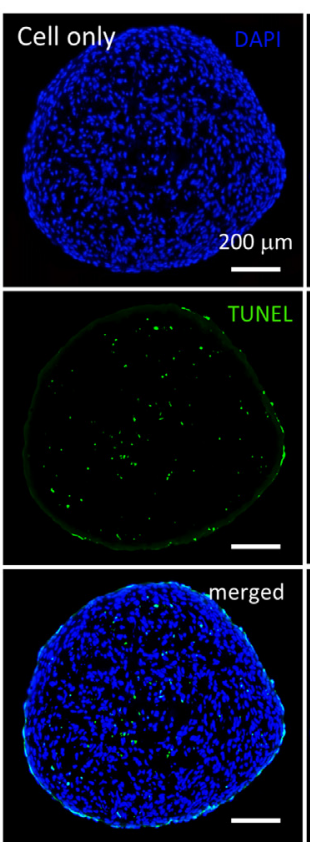
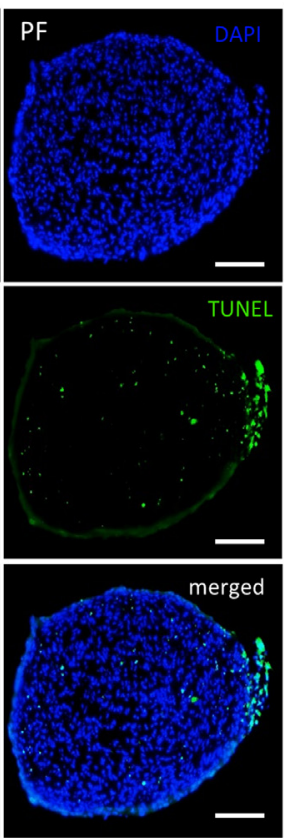

\section{E-PF}
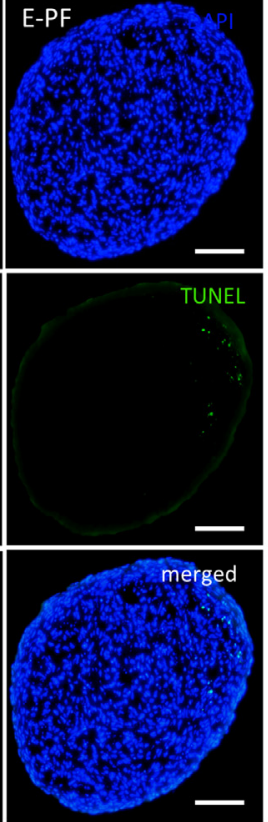

(b)

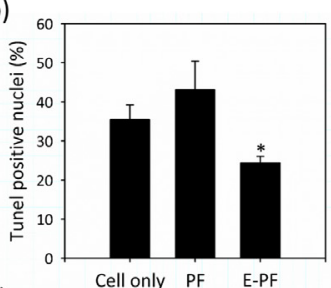

(c)

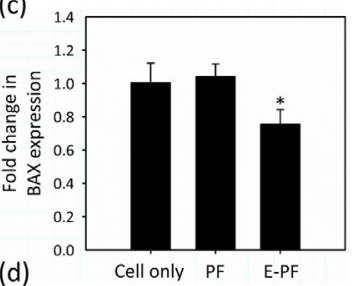

(d)

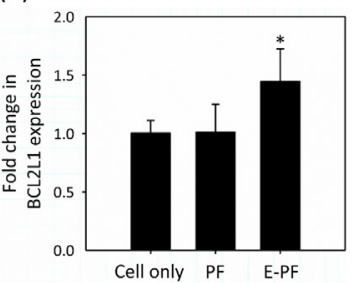

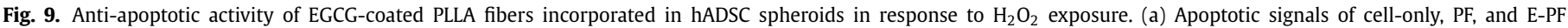
spheroids and (b) percentage of TUNEL-positive nuclei (\%). (c) Relative expression of (d) BAX and (f) BCL2L1 in cell-only, PF and E-PF spheroids (* p < 0.05).

(a)
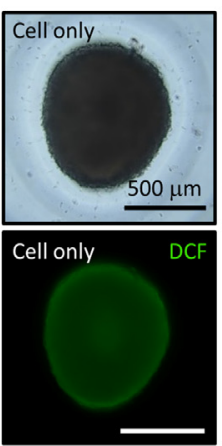

(c)

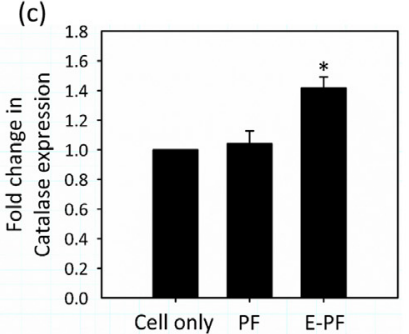

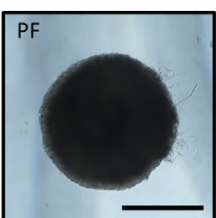

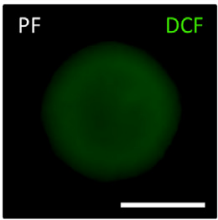

(d)

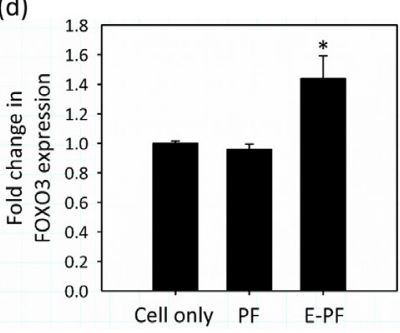

(b)
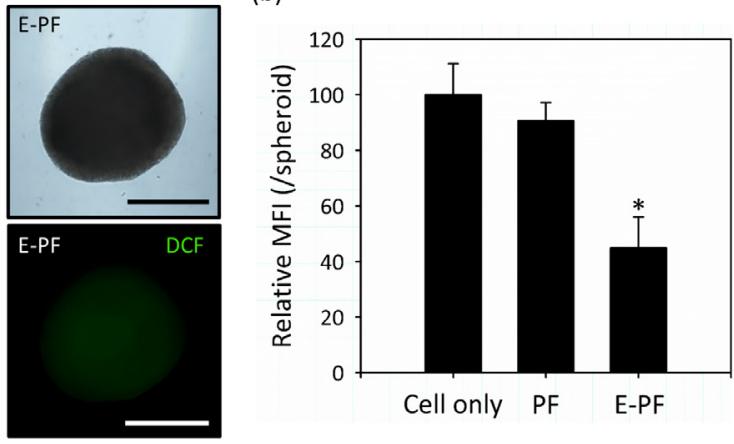

(e)

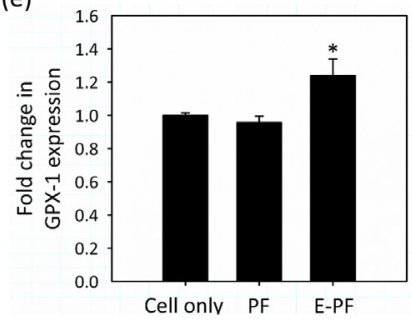

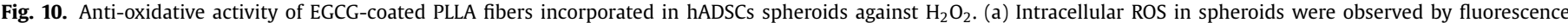

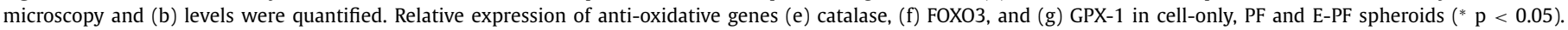

served in the cell-only $(45 \pm 13 \%)$ and PF $(85 \pm 6 \%)$ spheroids, while there was no deformation of spheroids incorporating E-PF ( $3 \pm 5 \%$ ) (Fig. 8a and b). There were more dead cells in cellonly and PF spheroids than in E-PF spheroids (Fig. 8c). Histological analysis of cross-sectioned spheroids revealed that cells were homogeneously distributed and tightly integrated throughout the spheroids (Fig. 8d) while in the PF group, deformation of spheroids at the periphery was observed (Fig. 8e). Our results indicate that cell damage due to diffusion of $\mathrm{H}_{2} \mathrm{O}_{2}$ in the media was localized at the periphery of the PF spheroids. Deformation (\%) was larger in the PF group than the cell-only group because the diffusion of $\mathrm{H}_{2} \mathrm{O}_{2}$ was mitigated by the relatively loosely formed networks between cells and fibers. In fact, histological images revealed a thicker cellular layer at the periphery of cell-only spheroids while the outer cell layer became thinner in spheroids containing fibers (Fig. 8d). The protective function of E-PF against $\mathrm{H}_{2} \mathrm{O}_{2}$ was evident. Necrotic core formation or external damage can lead to contraction and eruption of spheroids and thus structural deformation of a spheroid can serve as an indicator of the integrity of the spheroid. For example, extensive DNA damage was observed in multicellular tumor spheroids (MCTSs) cultured with $\mathrm{H}_{2} \mathrm{O}_{2}(0.1-5 \mathrm{mM})$ for $1 \mathrm{hr}$, resulting in structural changes [51], while laser irradiation of MSC 
spheroids caused destruction from the outside of the spheroid [52]. Our results indicate that the presence of E-PF protected against ROS damage.

There was a large number of TUNEL-positive nuclei in the $\mathrm{PF}$ group in the region of deformation (Fig. 9a), and the number of TUNEL-positive nuclei was significantly decreased in E-PF spheroids $(24 \pm 2 \%$ ) compared to cell-only spheroids (35 $\pm 4 \%$ ) and PF spheroids (43 $\pm 7 \%$ ) (Fig. 9b). Expression level of the apoptotic gene BAX was significantly lower in E-PF spheroids than in cell-only and PF spheroids (Fig. 9c), and conversely, the expression of the anti-apoptotic gene BCL2L1 was significantly higher in E-PF spheroids than in cell-only and PF spheroids (Fig. 9d). Intracellular ROS levels in spheroids were determined after $\mathrm{H}_{2} \mathrm{O}_{2}$ treatment. The relative MFI per spheroid was $45 \pm 11$ for E-PF spheroids, which was significantly lower than that in PF spheroids $(90 \pm 7)$ and cellonly spheroids $(100 \pm 11)$ (Fig. 10a and b). Catalase, FOXO-3, and GPX-1 expression was significantly higher in E-PF spheroids than cell-only and PF spheroids (Fig. 10c, d, and e). Consistent with a previous report that intraperitoneal injection of EGCG $(70 \mathrm{mg} / \mathrm{kg}$ ) improved expression of the anti-oxidative enzyme GPX-1 in hepatic tissue [36], EGCG-coated fibers appear to modulate hADSC signaling in spheroids, resulting in improved anti-oxidative enzyme expression. Our research group has been investigating strategies to deliver instructive signals to cells inside spheroids by incorporating biofunctionalized fibers into the spheroids during spheroid generation. This approach could efficiently direct and modulate cellular activities within spheroids. For example, fibers have been functionalized with PDGF to improve the proliferation of hADSCs within spheroids [53] and to enhance osteogenic differentiation through adenosine immobilization and mineralization [54,55]. Our results suggest that incorporating EGCG-coated fibers in spheroids confers the spheroids with sustained anti-oxidative properties and modulates signaling by cells inside the spheroid.

\section{Conclusions}

In this study, PCL surfaces were coated with EGCG in the presence of $\mathrm{Na}^{+}$or $\mathrm{Mg}^{2+}$ cations via MPN formation, and the TPC was greater in the presence of $\mathrm{Mg}^{2+}$ than $\mathrm{Na}^{+}$. EGCG coating increased surface hydrophilicity and roughness proportional to the TPC. EGCG coating maintained its anti-oxidative properties as confirmed by Fe conversion and ABTS radical scavenging activity of hADSCs cultured on EGCG-coated surfaces in the presence of $\mathrm{H}_{2} \mathrm{O}_{2}$. EGCG coating directly removed surrounding $\mathrm{H}_{2} \mathrm{O}_{2}$ and modulated signaling in hADSCs, leading to a decrease in expression of the apoptotic gene BAX and an increase in the expression of the antiapoptotic genes BCL2 and BCL2-L1 as well as the anti-oxidative enzymes catalase, FOXO3, and GPX-1. Furthermore, EGCG-coated PLLA fibers exhibited anti-oxidative properties as evidenced by $\mathrm{Fe}$ conversion, ABTS radical scavenging activity, and removal of $\mathrm{H}_{2} \mathrm{O}_{2}$. EGCG-coated PLLA fibers incorporated in stem cell spheroids reduced apoptotic signals in the presence of $\mathrm{H}_{2} \mathrm{O}_{2}$-induced oxidative stress and induced anti-oxidative enzyme expression relative to cell-only spheroids and spheroids incorporating fibers without an EGCG coating. In conclusion, EGCG coating can effectively protect against ROS-induced oxidative damage, suggesting its potential versatility in various tissue engineering applications.

\section{Declaration of Competing Interest}

The authors declare that they have no known competing financial interests or personal relationships that could have appeared to influence the work reported in this paper.

\section{Acknowledgements}

This research was supported by National Research Foundation of Korea (NRF) grants funded by the Korean government (MEST) (NRF-2019R1A2C2084965, NRF-2020R1A4A3078645).

\section{Supplementary materials}

Supplementary material associated with this article can be found, in the online version, at doi:10.1016/j.actbio.2021.02.005.

\section{References}

[1] M. Dizdaroglu, P. Jaruga, Mechanisms of free radical-induced damage to DNA, Free Radic. Res. 46 (2012) 382-419, doi:10.3109/10715762.2011.653969.

[2] R. Félix, P. Valentão, P.B. Andrade, C. Félix, S.C. Novais, M.F.L. Lemos, Evaluating the in vitro potential of natural extracts to protect lipids from oxidative damage, Antioxidants 9 (2020) 1-29, doi:10.3390/antiox9030231.

[3] E. Mijiritsky, L. Ferroni, C. Gardin, O. Peleg, A. Gultekin, A. Saglanmak, L.G. Delogu, D. Mitrecic, A. Piattelli, M. Tatullo, B. Zavan, Presence of ROS in inflammatory environment of peri-implantitis tissue: in vitro and in vivo human evidence, J. Clin. Med. 9 (2019) 38, doi:10.3390/jcm9010038.

[4] D. Pietropaoli, E. Ortu, M. Severino, I. Ciarrocchi, R. Gatto, A. Monaco, Glycation and oxidative stress in the failure of dental implants: a case series, BMC Res. Notes. 6 (2013) 1-6, doi:10.1186/1756-0500-6-296.

[5] A.M. Evens, J. Mehta, L.I. Gordon, Rust and corrosion in hematopoietic stem cell transplantation: the problem of iron and oxidative stress, Bone Marrow Transplant 34 (2004) 561-571, doi:10.1038/sj.bmt.1704591.

[6] G.G.A. Silkstone, M. Simons, B.S. Rajagopal, T. Shaik, B.J. Reeder, C.E. Cooper, O. Thews, J.C. LaManna, D.K. Harrison, G.G.A. Silkstone, M. Simons, B.S. Rajagopal, T. Shaik, B.J. Reeder, C.E. Cooper, Novel Redox Active Tyrosine Mutations Enhance the Regeneration of Functional Oxyhemoglobin from Methemoglobin: Implications for Design of Blood Substitutes., United States, 2018. 10.1007/9783-319-91287-5_70.

[7] W. Razzell, I.R. Evans, P. Martin, W. Wood, Calcium flashes orchestrate the wound inflammatory response through duox activation and hydrogen peroxide release, Curr. Biol. 23 (2013) 424-429, doi:10.1016/j.cub.2013.01.058.

[8] S. Franz, S. Rammelt, D. Scharnweber, J.C. Simon, Immune responses to implants - a review of the implications for the design of immunomodulatory biomaterials, Biomaterials 32 (2011) 6692-6709, doi:10.1016/j.biomaterials.2011. 05.078 .

[9] H. Blaser, C. Dostert, T.W. Mak, D. Brenner, TNF and ROS Crosstalk in Inflammation, Trends Cell Biol. 26 (2016) 249-261, doi:10.1016/j.tcb.2015.12.002.

[10] C.C. Huang, W.Y. Pan, M.T. Tseng, K.J. Lin, Y.P. Yang, H.W. Tsai, S.M. Hwang, Y. Chang, H.J. Wei, H.W. Sung, Enhancement of cell adhesion, retention, and survival of HUVEC/cbMSC aggregates that are transplanted in ischemic tissues by concurrent delivery of an antioxidant for therapeutic angiogenesis, Biomaterials 74 (2016) 53-63, doi:10.1016/j.biomaterials.2015.09.043.

[11] W. Zeng, J. Xiao, G. Zheng, F. Xing, G.L. Tipoe, X. Wang, C. He, Z.Y. Chen, Y. Liu, Antioxidant treatment enhances human mesenchymal stem cell antistress ability and therapeutic efficacy in an acute liver failure model, Sci. Rep. 5 (2015) 1-17, doi:10.1038/srep11100.

[12] L. Zhang, Y. Ma, X. Pan, S. Chen, H. Zhuang, S. Wang, A composite hydrogel of chitosan/heparin/poly ( $\gamma$-glutamic acid) loaded with superoxide dismutase for wound healing, Carbohydr. Polym. 180 (2018) 168-174, doi:10.1016/j.carbpol. 2017.10.036,

[13] D.B. Zorov, M. Juhaszova, S.J. Sollott, Mitochondrial reactive oxygen species (ROS) and ROS-induced ROS release, Physiol. Rev. 94 (2014) 909-950, doi:10. 1152/physrev.00026.2013.

[14] Y. Deldar, Y. Pilehvar-Soltanahmadi, M. Dadashpour, S. Montazer Saheb, M. Rahmati-Yamchi, N. Zarghami, An in vitro examination of the antioxidant, cytoprotective and anti-inflammatory properties of chrysin-loaded nanofibrous mats for potential wound healing applications, Artif. Cells, Nanomed. Biotechnol. 46 (2018) 706-716, doi:10.1080/21691401.2017.1337022.

[15] S. Zhang, J. Hou, Q. Yuan, P. Xin, H. Cheng, Z. Gu, J. Wu, Arginine derivatives assist dopamine-hyaluronic acid hybrid hydrogels to have enhanced antioxidant activity for wound healing, Chem. Eng. J. 392 (2019) 123775, doi:10.1016/j.cej. 2019.123775.

[16] T.Y. Yen, Z.R. Stephen, G. Lin, Q. Mu, M. Jeon, S. Untoro, P. Welsh, M. Zhang, Catalase-functionalized iron oxide nanoparticles reverse hypoxiainduced chemotherapeutic resistance, Adv. Healthc. Mater. 8 (2019) 1-8, doi:10.1002/adhm.201900826.

[17] S.K. Madhurakkat Perikamana, J. Lee, Y. Bin Lee, Y.M. Shin, E.J. Lee, A.G. Mikos, H. Shin, Materials from Mussel-inspired chemistry for cell and tissue engineering applications, Biomacromolecules 16 (2015) 2541-2555, doi:10.1021/ acs.biomac.5b00852.

[18] D.G. Barrett, T.S. Sileika, P.B. Messersmith, Molecular diversity in phenolic and polyphenolic precursors of tannin-inspired nanocoatings, Chem. Commun. 50 (2014) 7265-7268, doi:10.1039/C4CC02961E.

[19] H. Ejima, J.J. Richardson, F. Caruso, Metal-phenolic networks as a versatile platform to engineer nanomaterials and biointerfaces, Nano Today 12 (2017) 136148, doi:10.1016/j.nantod.2016.12.012. 
[20] V. Sanna, N. Pala, G. Dessì, P. Manconi, A. Mariani, S. Dedola, M. Rassu, C. Crosio, C. laccarino, M. Sechi, Single-step green synthesis and characterization of gold-conjugated polyphenol nanoparticles with antioxidant and biological activities, Int. J. Nanomed. 9 (2014) 4935-4951, doi:10.2147/IJN.S70648.

[21] T.S. Sileika, D.G. Barrett, R. Zhang, K.H.A. Lau, P.B. Messersmith, Colorless multifunctional coatings inspired by polyphenols found in tea, chocolate, and wine, Angew. Chemie - Int. Ed. 52 (2013) 10766-10770, doi:10.1002/anie.201304922.

[22] W. Wang, Q. Tang, T. Yu, X. Li, Y. Gao, J. Li, Y. Liu, L. Rong, Z. Wang, H. Sun, H. Zhang, B. Yang, Surfactant-free preparation of Au@Resveratrol hollow nanoparticles with photothermal performance and antioxidant activity, ACS Appl. Mater. Interfaces 9 (2017) 3376-3387, doi:10.1021/acsami.6b13911.

[23] C. Steffi, Z. Shi, C.H. Kong, S.W. Chong, D. Wang, W. Wang, Use of polyphenol tannic acid to functionalize titanium with strontium for enhancement of osteoblast differentiation and reduction of osteoclast activity, Polymers (Basel) 11 (2019) 10-12, doi:10.3390/polym11081256.

[24] B. Zhang, R. Yao, L. Li, Y. Wang, R. Luo, L. Yang, Y. Wang, Green tea polyphenol induced $\mathrm{Mg} 2+$-rich multilayer conversion coating: toward enhanced corrosion resistance and promoted in situ endothelialization of AZ31 for potential cardiovascular applications, ACS Appl. Mater. Interfaces 11 (2019) 41165-41177, doi:10.1021/acsami.9b17221.

[25] S. Lee, Y.Y. Chang, J. Lee, S.K. Madhurakkat Perikamana, E.M. Kim, Y.H. Jung, J.H. Yun, H. Shin, Surface engineering of titanium alloy using metal-polyphenol network coating with magnesium ions for improved osseointegration, Biomater. Sci. 8 (2020) 3404-3417, doi:10.1039/d0bm00566e.

[26] M.J. Moreno-Vásquez, E.L. Buitimea-Valenzuela, M. Plascencia-Jatomea, J.C. Encinas-Encinas, F. Rodríguez-Félix, S. Sánchez-Valdes, E.C. Rosas-Burgos, V.M. Ocaño-Higuera, A.Z. Graciano-Verdugo, Functionalization of chitosan by a free radical reaction: characterization, antioxidant and antibacterial potential, Carbohydr. Polym. 155 (2017) 117-127, doi:10.1016/j.carbpol.2016.08.056.

[27] J. Guo, B.L. Tardy, A.J. Christofferson, Y. Dai, J.J. Richardson, W. Zhu, M. Hu, Y. Ju, J. Cui, R.R. Dagastine, I. Yarovsky, F. Caruso, Modular assembly of superstructures from polyphenol-functionalized building blocks, Nat. Nanotechnol. 11 (2016) 1105-1111, doi:10.1038/nnano.2016.172.

[28] J.S. Lee, J.S. Lee, M.S. Lee, S. An, K. Yang, K. Lee, H.S. Yang, H. Lee, S.W. Cho, Plant flavonoid-mediated multifunctional surface modification chemistry: catechin coating for enhanced osteogenesis of human stem cells, Chem. Mater. 29 (2017) 4375-4384, doi:10.1021/acs.chemmater.7b00802.

[29] S. Geißler, A. Barrantes, P. Tengvall, P.B. Messersmith, H. Tiainen, Deposition kinetics of bioinspired phenolic coatings on titanium surfaces, Langmuir 32 (2016) 8050-8060, doi:10.1021/acs.langmuir.6b01959.

[30] H. Ejima, J.J. Richardson, K. Liang, J.P. Best, M.P. Van Koeverden, G.K. Such, J. Cui, F. Caruso, One-step assembly of coordination complexes, Science 341 (2013) 154-157 80-

[31] L. Panzella, G. D’Errico, G. Vitiello, M. Perfetti, M.L. Alfieri, A. Napolitano, M. D'Ischia, Disentangling structure-dependent antioxidant mechanisms in phenolic polymers by multiparametric EPR analysis, Chem. Commun. 54 (2018) 9426-9429, doi:10.1039/c8cc05989f.

[32] J. Ouyang, K. Zhu, Z. Liu, J. Huang, Prooxidant effects of epigallocatechin-3gallate in health benefits and potential adverse effect, Oxid. Med. Cell. Longev. (2020) 2020, doi:10.1155/2020/9723686.

[33] H.S. Kim, M.J. Quon, J.a. Kim, New insights into the mechanisms of polyphenols beyond antioxidant properties; lessons from the green tea polyphenol, Redox Biol. 2 (2014) 187-195, doi:10.1016/j.redox.2013.12.022.

[34] Q. Li, W. Xiao, F. Zhang, Q. Liu, J. Ye, H. Dong, X. Cao, Tannic acid-derived metal-phenolic networks facilitate PCL nanofiber mesh vascularization by promoting the adhesion and spreading of endothelial cells, J. Mater. Chem. B 6 (2018) 2734-2738, doi:10.1039/c8tb00350e.

[35] J. Meng, G. Yang, L. Liu, Y. Song, L. Jiang, S. Wang, Cell adhesive spectra along surface wettability gradient from superhydrophilicity to superhydrophobicity, Sci. China Chem. 60 (2017) 614-620, doi:10.1007/s11426-016-9031-8.

[36] J.H. Shin, H.J. Jeon, J. Park, M.S. Chang, Epigallocatechin-3-gallate prevents oxidative stress-induced cellular senescence in human mesenchymal stem cells via Nrf2, Int. J. Mol. Med. 38 (2016) 1075-1082, doi:10.3892/ijmm.2016.2694.

[37] Z. Li, J. Zhang, Y. Fu, L. Yang, F. Zhu, X. Liu, Z. Gu, Y. Li, Antioxidant shape amphiphiles for accelerated wound healing, J. Mater. Chem. B 8 (2020) 70187023, doi:10.1039/d0tb00578a.
[38] Z. Li, H. Li, J. Zhang, X. Liu, Z. Gu, Y. Li, Ultrasmall nanoparticle ROS scavengers based on polyhedral oligomeric silsesquioxanes, Chin. J. Polym. Sci. (English Ed. 38 (2020) 1149-1156, doi:10.1007/s10118-020-2486-7.

[39] S. Selvaraj, N.N. Fathima, Fenugreek incorporated silk fibroin nanofibers - a potential antioxidant scaffold for enhanced wound healing, ACS Appl. Mater. Interfaces 9 (2017) 5916-5926, doi:10.1021/acsami.6b16306.

[40] Y. Huang, Z. Du, P. Wei, F. Chen, B. Guan, Z. Zhao, X. Zhang, Q. Cai, J. Mao, $\mathrm{H}$. Leng, X. Yang, Biodegradable microspheres made of conductive polyorganophosphazene showing antioxidant capacity for improved bone regeneration, Chem. Eng. J. 397 (2020) 125352, doi:10.1016/j.cej.2020.125352.

[41] C.V. Suschek, O. Schnorr, K. Hemmrich, O.A. Lars-Oliver Klotz, H. Sies, V. KolbBachofen, Critical role of L-arginine in endothelial cell survival during oxidative stress, Circulation 107 (2003) 2607-2614, doi:10.1161/01.CIR.0000066909. 13953.F1.

[42] I.P. Shanura Fernando, M. Kim, K.T. Son, Y. Jeong, Y.J. Jeon, Antioxidant activity of marine algal polyphenolic compounds: a mechanistic approach, J. Med. Food. 19 (2016) 615-628, doi:10.1089/jmf.2016.3706.

[43] J.K. Lee, K.L. Walker, H.S. Han, J. Kang, F.B. Prinz, R.M. Waymouth, H.G. Nam, R.N. Zare, Spontaneous generation of hydrogen peroxide from aqueous microdroplets, Proc. Natl. Acad. Sci. USA 116 (2019) 19294-19298, doi:10.1073/pnas. 1911883116.

[44] C.J. Miller, A.L. Rose, T.D. Waite, Hydroxyl radical production by H2O2mediated oxidation of $\mathrm{Fe}(\mathrm{II})$ complexed by suwannee river fulvic acid under circumneutral freshwater conditions, Environ. Sci. Technol. 47 (2013) 829-835, doi:10.1021/es303876h.

[45] T. Cao, X. Zhang, D. Yang, Y.Q. Wang, Z.D. Qiao, J.M. Huang, P. Zhang, Antioxidant effects of epigallocatechin-3-gallate on the aTC1-6 pancreatic alpha cell line, Biochem. Biophys. Res. Commun. 495 (2018) 693-699, doi:10.1016/j.bbrc. 2017.11.006.

[46] X. Yan, Y. Li, H. Yu, W. Wang, C. Wu, Y. Yang, Y. Hu, X. Shi, J. Li, Epigallocatechin-3-gallate inhibits $\mathrm{H} 2 \mathrm{O} 2$-induced apoptosis in mouse vascular smooth muscle cells via 67kD laminin receptor, Sci. Rep. 7 (2017) 1-10, doi:10.1038/s41598-017-08301-6.

[47] M. Eskandari, J. Rembiesa, L. Startaitè, A. Holefors, A. Valančiūtè, F. Faridbod, M.R. Ganjali, J. Engblom, T. Ruzgas, Polyphenol-hydrogen peroxide reactions in skin: In vitro model relevant to study ROS reactions at inflammation, Anal. Chim. Acta 1075 (2019) 91-97, doi:10.1016/j.aca.2019.05.032.

[48] T.S. Li, E. Marbán, Physiological levels of reactive oxygen species are required to maintain genomic stability in stem cells, Stem Cells 28 (2010) 1178-1185, doi:10.1002/stem.438.

[49] A. Barzegar, A.A. Moosavi-Movahedi, Intracellular ROS protection efficiency and free radical-scavenging activity of curcumin, PLoS One 6 (2011) 1-7, doi:10. 1371/journal.pone.0026012.

[50] J.D. Lambert, R.J. Elias, The antioxidant and pro-oxidant activities of green tea polyphenols: a role in cancer prevention, Arch. Biochem. Biophys. 501 (2010) 65-72, doi:10.1016/j.abb.2010.06.013.

[51] F. Judée, C. Fongia, B. Ducommun, M. Yousfi, V. Lobjois, N. Merbahi, Short and long time effects of low temperature Plasma Activated Media on 3D multicellular tumor spheroids, Sci. Rep. 6 (2016), doi:10.1038/srep21421.

[52] N.V. Kosheleva, I.V. Ilina, I.M. Zurina, A.E. Roskova, A.A. Gorkun, A.V. Ovchinnikov, M.B. Agranat, I.N. Saburina, Laser-based technique for controlled damage of mesenchymal cell spheroids: a first step in studying reparation in vitro, Biol. Open 5 (2016) 993-1000, doi:10.1242/bio.017145

[53] J. Lee, S. Lee, T. Ahmad, S.K. Madhurakkat Perikamana, J. Lee, E.M. Kim, H. Shin, Human adipose-derived stem cell spheroids incorporating plateletderived growth factor (PDGF) and bio-minerals for vascularized bone tissue engineering, Biomaterials 255 (2020), doi:10.1016/j.biomaterials.2020.120192.

[54] L. Zhang, S.S. Wan, C.X. Li, L. Xu, H. Cheng, X.Z. Zhang, An adenosine triphosphate-responsive autocatalytic fenton nanoparticle for tumor ablation with self-supplied $\mathrm{H} 202$ and acceleration of $\mathrm{Fe}(\mathrm{III}) / \mathrm{Fe}(\mathrm{II})$ conversion, Nano Lett. 18 (2018) 7609-7618, doi:10.1021/acs.nanolett.8b03178.

[55] T. Ahmad, H.J. Shin, J. Lee, Y.M. Shin, S.K.M. Perikamana, S.Y. Park, H.S. Jung, H. Shin, Fabrication of in vitro 3D mineralized tissue by fusion of composite spheroids incorporating biomineral-coated nanofibers and human adiposederived stem cells, Acta Biomater 74 (2018) 464-477, doi:10.1016/j.actbio.2018. 05.035 